\title{
Neue Forschungen zur Genovefa-Sage ${ }^{1}$ ).
}

Beiträge zur Kirchen- und Kulturgeschichte des Rheinlandes.

Von

Dr. phil. Franz Görres zu Bonn.

Einleitung.

Die anmuthige Erzählung von der Pfalzgräfin Genovefa hat sich seit dem 17. Jh. nicht bloss in der mittelrheinischen Bevölkerung, sondern auch weit über die rheinischen Gauen, ja über die Grenzen Deutschlands hinaus so sehr eingebürgert, dass man sie unbedenklich den beliebtesten Sagen des deutschen Volkes einreihen darf. Kein Wunder also, dass diese Legende von jeher auch die rege Aufmerksamkeit der Geschichtsfreunde zu fesseln gewusst hat. Man war vielfach bemüht, die im Volksmunde stets

1) Vgl. hierzu Bernhard Seuffert, Die Legende von der Pfalzgräfin Genovefa (Habilitationsschrift), Würzburg 1877, 85 S., Felix Brüll, Die Maifelder Genovefa, Jahresbericht des Progymnasiums zu Andernach für... 1896/97, Andernach 1897, 17 S., Const. Koenen, Anzeige der' Brüll'schen Studie „über den Ursprung der Genovefa-Legende", Rheinische Geschichtsblätter, 3. Jahrgang, Bonn 1897, Nr. 6, 4. S. 188-191 (hier werden sämmtliche Ergebnisse Brülls kurz zusammengestellt und zustimmend besprochen), linickenbergs wohlwollende Recension der Brüll'schen Genovefa, Bonner Jahrbücher, Heft 101 (1897), S. 165 f., Paul Lehfeldt, Bau- und Kunstdenkmäler des Rgbz. Coblenz, Düsseldorf 1886 und Franz Görres, Kritische Erörterungen über die Entstehungsgeschichte der Genovefa-Sage, Pick'sche Monatsschrift Jahrg. II, 1876, Heft 10/12, S. 531-582, Derselbe, Anzeige der Seuffert'schen Genovefa, Pick'sche Monatsschrift IV (1878), H. 3, S. 160 -170, Derselbe, Die Legende von der Pfalzgräfn Genovefa, Westdeutsche Zeitschrift VI, 1887, S. 218-230. 
fortlebende Erzählung wissenschaftlich zu prïfen, zu zergliedern und eine befriedigende Deutung für das Ganze zu finden. Aber diese Erklärungsversuche führten, entsprechend dem verschiedenen kritischen Standpunkte, von dem man bei der Untersuchung ausging, stets zu entgegengesetzten Ergebnissen. Man bat die in Rede stehende Erzählung geradezn als ausreichend verbürgte Thatsache aufgefasst und demgemäss den Pfalzgrafen Siegfried, seine Gemahlin, den Ritter Golo u. s. w. als rein geschichtliche Persönlichkeiten gelten lassen; die Vertreter dieser Auffassung haben die Erzäblung nacheinander ins 7., 8., 10., 11., 12. und 13. Jh. versetzt ${ }^{1}$, Andere fassen die ganze Geschichte als Sage auf und versuchen eine mythologische Deutung. Manche Forscher wollen auch in der Genovefa-Geschichte nur efne gänzlich nnverbürgte Legende erblicken.

Angeregt durch die tüchtige fleissige Abhandlung Brülls über die Maifelder Genovefa (s. oben S. 1 Anm. 1), habe ich die Ergebnisse mehr als 20 jähriger ernster Forschungen über den interessanten Gegenstand, die ich in drei Artikeln friiher veröffentlicht, vervollständigt und vertieft und bin jetzt in der Lage, in den folgenden Blättern einen ganz neuen Genovefa-Aufsatz vorzulegen, der freilich, um leidige Wiederholungen von früher Gesagtem thunlichst $\mathrm{zu}$ vermeiden, nicht das Ganze erschöpfend behandeln, sondern bloss einige besonders wichtige und interessante Streitpunkte gründlicher, als dies bisher geschehen konnte, erörtern soll. Es freut mich, dass ich alle frïher aufgestellten Sätze aufrecht halten kann, und dass, wie einst Seuffert (s. S. 1 Anm. 1), so jetzt Brüll, völlig unabbängig von mir arbeitend, im Wesentlichen zu denselben oder doch ähnlichen Resultaten gelangt sind.

1) Einzelne dieser hyperconservativen Forscher, namentlich Sauerborn, Die Erzählung von der Pfalzgräfin Genovefa, Regensburg 1856, S. 41) und der Benedictiner Kupp (in seiner „Dissertatio Genovefica“ bei Sauerborn S. 3-45), machen die Genovefa sogar zu einem Mit. glied des Hauses der Pippiniden; ihre Eltern sollen Pippin von Heristal und Plectrudis gewesen sein. In einem lateinisch geschriebenen $\mathbf{P}$ farrbuch von Nickenich im Maifelde aus dem zu Ende gehenden 18. Jh. findet sich sogar ein förmlicher Stammbaum Genovefas; auch hier heisst sie eine Tochter des mittleren Pippin, und ihr Tod wird auf den 2. April 750 angesetzt (vgl. Sauerborn, S. 142). Mit Fug lehnt Brüll a. a.0. S. 17 diese widersinnige Genealogie entschieden ab. 
Die wichtigsten Ergebnisse der Seuffert-Britll'schen Forschungen, so weit sie sich in der Hauptsache mit den meinigen decken, sind folgende:

1. Die Sage lässt sich nicht mythologisch deuten, wie dies Seitens der Germanisten Jakob Grimm, Leo, Hocker, Zacher, Simrock u. A. geschehen ist.

2. Siegfried, Genovefa, Golo u. s. w. durfen nicht mit dem Benedictiner Kupp, Sauerborn u. A. als geschichtliche Persön. lichkeiten aufgefasst werden (s. oben S. 2 Anm. 1).

3. Der historische Pfalzgraf Siegfried, der zweite Gründer der Benedictiner-Abtei Laach, ist der Held unserer Legende geworden.

4. Die Entstehung und Ausbildung der Sage fällt in das Jahrhundert von 1325 bis etwa 1425, in einen Zeitraum, in dem alle Nachrichten über die Kapelle Frauenkirchen fehlen.

5. Man hat in der Erzählung von der Pfalzgräfin Genovefa eine ursprünglich und zum mindesten bis tief ins 16 . Jh. hinein streng lokalisirte, an die Kapelle Frauenkirchen sich anlebnende, auf Laach und die nächsten Umgebungen, auf das sog. Maifeld, beschränkte Marienlegende zu erblicken.

Satz 1 ist die Hauptsache: In der That darf als das wichtigste Ergebniss der scharfsinnigen Kritik Seufferts gelten, dass sie die absolute Unmöglichkeit einer mythologischen Deutung der Marienlegende des 14. bezw. des 15. Jhs. überzeugend dargethan hat. In mythologischer Auffassung deutscher Sagen haben einige Germanisten mitunter einen völlig unberechtigten Eifer bekundet. Hat man doch sogar in der legendarischen heiligen Ursula die altdeutsche (niederrheinische), durch Inschriften der späteren römischen Kaiserzeit bezeugte Göttin Nebalennia wittern wollen.

Seuffert rügt mit Fug das Verfahren Simrocks (Rheinland 1847, S. 308), der „in der Vergleichung (der Siselia- und Genovefasage) so weit geht, dass er den von P. Cerisiers, den weiter unten zu erwäbnenden Verfasser eines Romans „Genovefa“, erfundenen Traum Siegfrieds von einem Drachen mit dem Drachen des Helden zusammenhält". Ebenso verwirft Seuffert mit Recht den Versuch Zachers (Historie von der Pfalzgräfin Genovefa, S. 54), ,sogar eine 1713 (!!) verbriefte Verpflicbtung Mayens, am Dreikönigentage Kohlen nach Frauenkirchen zu liefern", mythologisch zu deuten! 


\section{Ueber den ursprünglichen Kern der Genovefa-Legende und spätere Erfindungen und Zuthaten, etwa seit der Mitte des. 17. Jahrhunderts.}

Da die ursprünglichste Form unserer Legende nur in den älteren Handschriften, die im 15. und zu Anfang des 16. Jahrhunderts zu Laach oder doch in der nächsten Umgebung dieser Abtei verfasst wurden, niedergelegt ist ${ }^{1}$ ), während sämmtliche moderne Bearbeitungen der Sage mit zablreichen höchst willkürlichen Erfindungen und Zuthaten verquickt sind, so liegt mir zum Verständniss der folgenden Untersuchungen die Aufgabe ob, den Leser mit dem Inhalte der urspringlichen Legende, im Allgemeinen wenigstens, bekannt zu machen. Dieser Verpflichtung wird am besten entsprochen, wenn ich zuerst auf einige charakteristische Züge, die sich in sämmtlichen Manuscripten übereinstimmend wiederfinden, hinweise und dann die wichtigsten Zuthaten ausdrücklich hervorbebe, mit denen die Legen de seit dem 17. Jh. ausgeschmückt wurde.

1. In ersterer Hinsicht ist vor Allem zu bemerken, dass sämmtliche Handschriften schon die Geschichte der Hirschkuh. haben ${ }^{2}$ ) and das Ganze in unmittelbare Verbindung mit der Ka-

1) Die jetzt der Forschung zugäuglichen alten handschriftlichen Biographien der Pfalzgräfin siud die von Sauerborn (Die Erzähinng von der Pfalzgräfin (jenovefá, Regensburg 1856) veröffentlichte Handschrift des Johann von Andernach anvi 1500, das Freher'sche Mse. - er hat es 1612 in seinen „Origines palatinae“, A ppendix part. II, S. 18-22 herausgegeben - und der Emyich'sche in der Trierischen Stadtbibliothek als Nr. 1444 (Ad gesta Trevir, Nr. V) Msc. I ZO beruhende Codex. Der sog. Archetypus, das Seinius'sche Msc. (etwa vom J. 1448), sowie der Hontheim'sche Codex sind leider verschollen. Was das gegenseitige Verbältniss dieser Handschriften betrifft, so nehme ich mit Seuffert (S. 2T-34) und Brüll (S. 4-6) an, dass Johaun von Andernacb, eine ältere Vorlage benutzend, den besten und reinsten rorhandenen Text bietet, dass weiter Emyich (anni 1472) jünger ist als der Seinius'sche und Hontheim'sche Codex, das Freher'sche Msc. und die Vorlage des Johann von Andernach und seinen Stoff schon hier und da ein wenig erweitert und ausgeschmückt hat. Uebrigens hat Matthias Emyich, gleichfalls ein Andernacher, sein Opus im Bopparder Karmeliterk loster, dem jetzigen Progymnasi um, verfasst.

2) Für die Geschichte der $\mathrm{Hirschkuh}$ liegt ein analoger $\mathrm{Zug}$ vor in der legendeubaft ausgeschmückten Lebensskizze des cappadocischen Mar- 
pelle Frauenkirchen bringen. Weiter gehört bereits zum Kern der Sage die Angabe, dass die Pfalzgräfin 6 Jahre und 3 Monate in der Wildniss zugebracht und am Tage vor dem Dreikönigsfeste (5. Januar) aufgefunden und bereits am 2. April desselben Jahres gestorben sei. Auch ist es charakteristisch, dass den Handschriften zufolge weder Golo noch der Pfalzgraf daran denken, den ungliicklichen Koch, den angeblichen Verfïhrer Genovefas, gleichfalls zu bestrafen. Anderseits berichten die Manuscripte einstimmig, ja mit Behagen, dass der Verräther Golo nach Entdeckung seiner Schuld auf Befehl des Pfalzgrafen von vier zottigen Ochsen zerrissen wurde.

2. Die Erfindungen und Zuthaten zur Genovefa-Legende, wie man sie in modernen Bearbeitungen liest, lassen sich alle, mittelbar wenigstens, auf das zuerst $1638 \mathrm{zu}$ Mons in Belgien erschienene Buch des Jesuiten René de Cerisiers "L'innoceuce reconnue ou vie de $S^{\text {te }}$. Geneviève de Brabant" und unmittelbar auf das hiernach bearbeitete niederländische und deutsche Volksbuch zurückführen. Der genannte Schriftsteller war bemüht, die Genovefa-Geschichte ibres Charakters einer lokalisirten Marienlegende zu entkleiden, zu einem erbaulichen religiösen Roman umzugestalten und den weitesten Kreisen zugänglich zu machen, und zu diesem Zweck hat er dęn einfachen Kern durch zahlreiche Zuthaten erweitert.

Was das sog. deutsche Volksbuch "Genovefa" betrifft, so ist es ein Büchelchen von unbekanntem Verfasser ${ }^{1}$ ); es ist in sehr

tyrers $\mathrm{M}$ a mas. Bereits $\mathrm{Greg}$ or von Nazianz (Homilia 44 c. XII bei Mi g n e, Patrol. Graeca XXXVI, Par. $1858=$ Opp. Gregorii Naz. II S. 620 f.

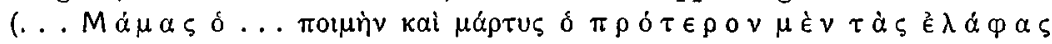

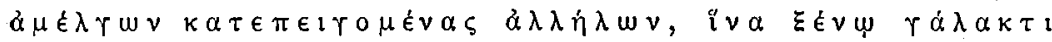

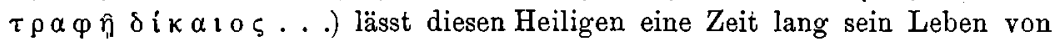
der Milch einer Hirschkuh oder vielmehr einer ganzen Schaar dieser harmlosen Thiere fristen.

1) Vgl. indess Brüll a. a. 0. S. 3 Anm. 1: . . Auf diese Quelle [Cerisiers' L'innocence reconnue] gehen auch die volksthïmlich gewordenen deutschen Bearbeitungen der Legende zurück. Für letztere ist von ganz besonderer Bedeutung gewesen die glückliche Fassung, welche der durch sein schönes Volksbuch vom Leben Christi rủhmlichst bekannte P. Martin Cochem († 1712) der Erzällung gab in seinem "Auserlesenen History-Buch"... Daraus wurde die Legende "von der bedrängten hl. Pfalzgräfin Genovefa" wörtlich, aber ohne Nennung des Verfassernamens zuerst um die Mitte des 18. Jahrhunderts zu Köln und seitdem immer wieder als "gedruckt in diesem Jahr" ausgegeben und unter dem Volke weit verbreitet. 
naivem Stile geschrieben und so betitelt: „Eine rübrende Historie von der Pfalzgräfin Genovefa, wie es ibr in Abwesenheit ihres herzlieben Ehegemahls ergangen ist. Gedruckt in diesem Jahr." „Unter allen den verschiedenen Büchern dieser Gattung ist die Genoveva durchaus das Geschlossenste und am meisten ausgerundete; stellenweise ganz vollendet, und in seiner anspruchslosen Natülichkeit unübertrefflich ausgeführt, im Ganzen in einem ruihrend unschuldigen Ton gebalten, kindlich, ungeschminkt, und in sich selbst beschattet und verdunkelnd im heiligen Geftibl"... (Jos ef Görres, Die teutschen Volksbücher, Heidelberg 1807, 46. (Genovefa [S. 246-250], S. 247). Diese kleine Schrift findet sich in überaus zahlreichen Exemplaren im Trierischen auf dem Lande verbreitet und macht häufig nebst biblischer Geschichte und Gesangbuch die ganze Buicherei des Banern aus.

3. Gehen wir jetzt zur Aufzählung einzelner Erfindungen Cerisiers ${ }^{1}$ ) und seiner Nachbeter iiber. Die Handschriften wissen zwar schon Manches iuber den kleinen Sohn der Pfalzgräfin zu berichten, verschweigen aber den Namen des Knaben. Cerisiers hat für ihn die biblische, Lib. Genes. 35, 18 entlebnte, Bezeichnnng „Benoni" d. i. „Sohn meines Schmerzes". Erst der Jesuit P. Michael Staudacher bat in seiner ersten deutschen Uebertragung der „L'innocence reconnue“" „Genovefa, das ist Wunderliches Leben . . . der H. Genovefa" ..., Dillingen 1660, „Benoni" mit

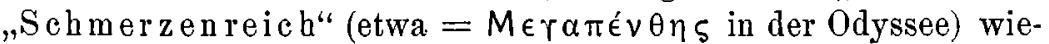
dergegeben, nnd dieser letztere Name fand auch Aufnahme im dentschen Volksbuch.

Den Koch kennen die Handschriften entweder gar nicht, oder sie erwähnen ibn zwar, lassen ihn aber straflos ausgeben. Cerisiers und seine Nachbeter wissen indess weit mehr über diesen Manu zu berichten. Natürlich wird er als angeblicher Ehebrecber gleichfalls zum Tode verurtheilt und auf Befehl Golos vergiftet. Der Unglitckliche kann auch nach dem Tode noch nicht zur Ruhe kommen. Sein Geist erscheint nach den meisten spätern Bearbeitungen unserer Legende dem Pfalzgrafen (nach vereinzelten Darstellungen dem trenlosen Burgvogt) im Schlafe und ruft ihm zu: „Genovefa ist unschuldig! Gottes Rache iiber die Verbrecher!“

1) Seuffert (S. 40-48) gibt einen trefflichen Auszug aus "L'innocence reconnue", diesem jetzt sehr selten gewordenen Buche; s. Brüll S. 3 Anm. 1. 
Ueber das letzte Schicksal Golos bringen die Neueren Angaben, die nicht nur mit der bezüglichen handschriftlichen Erzählung; sondern theilweise auch unter sich differiren. Da lässt z. B. Christoph Schmid in seiner "Genovefa" die Pfalzgräfin, als ihre Unschuld zu Tage gekommen, sich bei ihrem Gemahl um Begnadigung des Verräthers verwenden. Ob diese grossmüthige Fürbitte Erfolg gehabt, darïber lauten die modernen Berichte sehr verschieden. Nach der einen Angabe wäre Golo gleichwohl der barbarischen Todesstrafe des Viertheilens nicht entgangen. Andere, so z. B. abermals Christoph Schmid, wollen wissen, der Verbrecher sei zu lebenslänglicher Kerkerhaft begnadigt worden. Nach einer dritten Erzählung hätte Golo gar als Selbstmörder geendigt. Diejenigen späteren Bearbeiter unserer.Legende, die in Uebereinstimmung mit den Handschriften an einer barbarischen Hinrichtung des Burgvogts festhalten, gesellen ihm als Ungliicksgefährtin auch noch die Zauberin aus Strassburg bei. Natiirlich muss diese Hexe - in einigen siiddeutschen Puppenspielen "Genovefa" heisst sie „Piata" -, ganz entsprechend dem im Zeitalter eines Cerisiers allgemein verbreiteten Wahne, den Feuertod erleiden.

Der französische Jesuit hat unsere Legende in der That zu einem Roman von europäischer, ja internationaler Berühmotheit umgeschaffen. Seuffert (S. 48-85) bietet interessante Nachweise über die seitdem sebr reichliche Genovefa-Literatur. Er führt uns die Fortbildung und Verbreitung der Sage in gebundener und ungebundener Rede, in dramatischer und volksthümlicher Bearbeitung vor. Wir sehen, wie sich die Sage nicht bloss weit über Deutsehlands Grenzen hinaus, in Italien, Frankreich, England, Skandinavien, sondern auch jenseits des Oceans bei unsern Landsleuten in der neuen Welt das Bürgerrecht erwirbt. Der ausserordentlich belesene Verfasser bietet keineswegs bloss trockene Nomenclatur, sondern eine lebensvolle kritische und ästhetische Würdigung der betreffenden Bearbeitungen. Besonders geeignet, unser Interesse zu beherrschen, sind seine ebenso sachkundigen als geistvollen Ausfïhrungen über das niederländische und deutsche Volksbuch „Genovefa" (S. 52-57,69-76), sowie iiber die bezüglichen Puppenspiele (S. 58.79 f.) $)^{1}$.

1) Brüll, der neueste verdienstliche Genovefa-Forscher, erklärt aus- 


\section{Die Entstehungsgeschichte der Genovefa-Legende (1325 bis etwa 1425).}

Unsere Erzählung von der Pfalzgräfin Genovefa darf man also nicht etwa als eine historische Thatsache auffassen. Man kann darin nur eine Sage erblicken, und zwar, allgemein betrachtet, eine sog. Wandersage, insofern Genovefa, wie Griseldis, das "leidende Weib" ist, im Einzelnen aufgefasst dagegen eine ursprünglich und zum mindesten bis tief ins 16 . Jh. hinein streng lokalisirte, an die Kapelle Franenkirchen sich anlehnende, auf Laach und die nächsten Umgebungen, auf das sog. Maifeld beschränkte Marienlegende; denn der Kultus der Himmelskönigin erscheint darin sehr stark aufgetragen: Die Rettung Genovefas vom Tode durch Mörderhand oder durch die Bestien der Wildniss, die Stillung des Knaben durch die Hirschkuh, sowie die Wiederauffindung der Pfalzgräfin und die Entdeckung ihrer Unschuld, Alles das wird der wunderbaren Einwirkung der von Genovefa andächtig verehrten Mutter des Heilandes zugeschrieben, und die Kajelle Franenkirchen wird zu Ehren derselben erbaut und eingeweiht. Wahrscheinlich ist unsere Legende anfänglich eine Fiction, „Dichtung“ eines Laacher Mönches, die sehr bald bei den Bewohnern des Maifeldes wegen der darin vorherrschenden überaus glücklichen harmonischen Verknüpfung älterer Sagestoffe, vor Allem aber wegen ihres einheitlichen, naiven, lokalpatriotischen Charakters den lebhaftesten Widerhall fand. Die Bewohner des Maifeldes hegen noch jetzt für ihre Pfalzgräfin Genovefa dieselbe lebhafte Begeisterung, wie die Schweizer für ihren Tell.

1. Zu Anfang des 13. Jh. (genauer um 1220) existirte unsere Legende noch nicht, sonst würde sie, wie schon Zacher (Genovefa Ersch-Gruber'sche Encyklopädie, 1. Section, 58. Theil, S. 220) richtig beobachtet hat, gewiss Cäsarius von Heisterbach, der älteste rheinische Novellist, dem unlängst der Bergische Geschichtsverein pietätroll eine Denktafel gestiftet hat, in seinem „Dialogus

drücklich (a. a. O. S. 6), auf die literarische Weiterbildung der Legende (seit Emyich, zumal seit Cerisiers und seinen Nachbetern) verzichten zu wollen [s. indess die inhaltreiche Notiz a. a. 0. S. 3 Anm. 1]; er meint u. A.: . . . ndie spätern ausführlichen Forschungen des Stoffes haben lediglich nur ein literarisches Interesse." 
miraculorum" (ed. Strange) ${ }^{1}$ ) verwerthet haben. Ist er doch eifrig bemüht, möglichst viele auffallende Madonnenmirakel zusammenzutragen ${ }^{2}$ ); von der wunderbaren Rettung Genovefas, die ihm doch sicher in seinen Context gepasst hätte, erzählt er aber kein Wort. Zweitens dieses Schweigen ist um so auffallender, als Cäsarius wohl in der Lage war, über eine etwa zu Laach circulirende, auf den Madonnencult bezïgliche Genovefa-Legende authentische Erkundigungen einzuziehen, wenn die dortigen "schwarzen Brüder" schon etwas von einer solchen Sage gewusst hätten: Aus Dist. IV c. 71, vol. I, S. 238 f. erbellt, dass ein Ordensbruder des Cäsarius mit den Laacher Verhältnissen genau bekannt war; verdankt er doch diesem Cistercienser-Collegen ein Beispiel der edlen Gastfreundschaft, wie sie damals zu Laach gepflegt wurde ${ }^{3}$ ).

Z utreffend urtheilt also Brïll (a. a. 0. S. 14): „Noch eine andere Beobachtung veranlasst dazu, die Abfassung der Vorlage unserer ältesten Handschriften in die späteren Jahrhunderte des Mittelalters zu verlegen. Wie schon Zacher und nach ihm Görres und Seuffert mit vollem Rechte betonen, würde wohl schwerjich unsere Legende dem Cäsarius von Heisterbach entgangen sein, wenn sie in den Manuskripten des Klosters Laach, mit dessen Ueberlieferungen sich dieser fleissige Sammler durchaus vertraut zeigt, im Anfange des dreizehnten Jahrhunderts schon vorhanden gewesen wäre. Wie gut die Geschichte in den Zusammenhang seines um 1220 erschienenen Dialogus miraculorum gepasst hätte, braucht nicht erst gesagt zu werden. Gerade die wunderbare Hülfe Marias bildet, wie in der Genovefa-Legende, so auch bei vielen Stïcken des Dialogus das Hauptmotiv.

2. Um 1220 existirte also unsere Legende noch nicht. Die ersten Keime der Entwicklungsgeschichte der Sage fallen vielmehr

1) Die wichtigste Handschrift, die der Strange'schen Ausgabe zu Grunde liegt, gehört zu den Beständen der Düsseldorfer Landesbibliothek.

2) Vgl. Dist. VII („De beata Maria“) c. 1-c. 59, vol. II, S. 1-80 und zumal c. 22. 23. 27. 28. 36. 45. 48. Mit diesen $\mathrm{E}$ in z el beispielen vergleiche man noch das begeisterte all.gemeine Urtheil des Cäsarius über die mächtige Wunderwirkung Mariens (Dist. VII, c. 1 a. a. O. S. 1-3).

3) Erläuterungsschriften über den Verfasser des „Dialogus miraculorum“: Herm. Cardauns, Art. Cäsarius in der Allg. deutsch. Biographie, Alex. Kaufmann ( + ), Cäsarius von Heisterbach, 2. Auf. Köln, 1862 und Annalen für die Gesch. des Niederrheins 1891, Doppelheft. 
erst etwa in den Anfang des 14. Jh. Ehe ich nun zu den Erwägungen übergehe, auf Grund deren ich zu dieser Annahme gelange, möge ein kurzes Wort über die geographische Lage der Kapelle Frauenkirchen, an die sich die fragliche Legende anlehnt, vorausgeschickt sein.

Die genaueste Angabe hierüber bietet P. Kupp (Sauerborn a. a. 0. S. 3): „Auf der weiten Fläche des Maifeldes zwischen Ochtendung und Mayen erblickt man eine ... gewöbnlich Frauenkirche genannte Kapelle ... Ihre Entfernung von Laach beträgt $11 / 2$ Stunden, von Andernach 2, von Coblenz 4 Stunden. In der nächsten Umgebung liegen die Orte Kruft, Thür und Niedermendig." Nach Lehfeldt a. a. O. S. 381 liegt die Capelle „nahe Thür, $7 \mathrm{~km}$ ostnordöstlich von Mayen"...

Die Capelle mag schon im 12. Jh. erbaut worden sein; wenigstens sollen architektonische Grïnde für diese Annahme sprechen, und das ursprüngliche mittlere Schiff, sowie der eigentliche Altar (ohne das Bildwerk auf demselben) noch aus dem 12. Jh. stammen (vgl. Wegeler, Laach I, S. 135, Anzeige von Zachers Genovefa, Annalen des histor. Vereins für den Niederrbein, Doppelheft $9 / 10$, S. 283 , Sauerborn, S. 153 f. nebst Zeichnung I, II, III, Lehfeldt, S. 384 und Brüll, S. 9 f.). Frauenkirchen wurde gestiftet ,als dreischiffige Basilika; das Langhaus ist romanisch". Seit der traurigen Säcularisation im J. 1804 ,,besteht die Kirche ... aus dem einschiffigen, jetzt vierjochigen Langhaus und dem Chor". . . (s. Lehfeldt, S. 384 f., vgl. auch Sanerborn, S. 4, Anm. 2, S. 154).

Frauenkirchen wird weder im 12., noch im 13. Jh. genannt; dagegen tritt es plötzlich zu Anfang des 14. Jh. ganz bedeutend in der Geschichte des Maifelds hervor : 1319 findet in der Kapelle die Unterzeichnung eines Friedensvertrages statt, der unter Vermittlung des Trierischen Erzbischofs Baldewin zwischen dem Kurfürsten Heinrich von Köln und der Stadt Köln selbst abgeschlossen wurde (cf. Gesta Baldewini de Luezemburch 1. III c. 3 bei Martène, Scriptores tom. IV, p. 407: ...,Quam pacem ipse dominus Baldewinus postea in Wrawenchirchen prope Andernacum benivole ordinavit." Unter dem 2. April 1325 bewilligen zwölf Bischöfe von Avignon aus der Kapelle Frauenkirchen und deren Besuchern einen Ablassbrief (nach dein im Coblenzer Staatsarchir aufbewahrten Original veröffentlicht von Sauerborn, S. 110 f.), und der in dieser lateinischen Urkunde bedingte Consens des „Dioecesanus loci“ wird unter dem 20. April 1326 nebst weiterem 
Ablass-Privilegium vom Erzbischof Baldewin ertheilt (Sauerborn, S. 112 f.). Ebenso wird unserer Kapelle in einer deutschen Urkunde vom 28. Juli 1327 gedacht (abgedruckt bei Günther, Cod. dipl. Rheno-Mosell. Theil III, Abth. 1, S. 250 f., Nr. 150 und Sauerborn S. 119). Sowohl der Ablassbrief von 1325 als auch die soeben erwähnte Urkunde von 1327 haben das damalige Bestehen einer geregelten Seelsorge zur Voraussetzung. In ersterem kommt schon der "capellanus" dicte capelle" vor, und in letzterer wird des „Kirchberrn" (patronus) von Frauenkirchen gedacht („deme Kirgherrin van Vrouwinkirgin").

Die Annahme, wonach die Kapelle schon seit dem 12. Jb. existirt hat, erbält also durch die bedeutsame Art, wie sie zwischen 1319 und 1327 gleich zum ersten Male in die Geschichte eingeführt wird, eine wenigstens indirecte Bestätigung. Da man nun fitr die Zeit vom 12. bis zum Beginn des 14. Jh. gar nichts tiber die Kapelle erfährt, so ist die Annahme nicht abzuweisen, dass Frauenkirchen, von Haus aus ein lange Zeit kanm beachtetes Gotteshaus, erst zu Anfang des 14. Jh. plötzlich eine unerwartete Bedeutung erlangte. Erst von da ab wird also Frauenkirchen, dessen Entstehung im Dunkeln lag, Gegenstand der Sagenbildung geworden sein. Keine Spur fübrt auf die Annabme der Gründung unserer Kapelle durch irgend ein angesehenes, im Maifelde ansässiges Geschlecht, etwa durch die unweit Mayen ansässigen Grafen von Virneburg, welche letztere freilich in drei Urkunden, in der uns schon bekannten rom 28. Juli 1327 and in zwei weitern Urkunden vom 10. Juli 1459 und vom 25. Juni 1461 (bei Sauerborn, S. 120-129) zu Frauenkirchen in Beziehung gebracht werden.

Die wahrscheinlichste Annahme bleibt die, dass unsere Legende um dieselbe Zeit zu entstehen begann, wo Franenkirchen zum ersten Mal in der Geschichte ansehnlich hervortrat, d. i. eben seit Anfang des 14. Jh. Zur Ausbildung der Sage mag wohl der Umstand mächtig beigetragen haben, dass sich in der Kirche, allerdings etwa erst seit Mitte des 14. Jh., die Grabdenkmale eines Ritters im Harnisch und einer Frau befanden, die man irrthümlich, so noch der unkritische P. Kupp (bei Sauerborn, S. 3-9), für die Denksteine Siegfrieds und Genovefas hielt (s. Wegeler, S. 135 Zeichnung IV am Schluss des Sauerborn'schen Buches, Lehfeldt, S. 385 und Brüll, S. 10 f.).

Die Sage mag spätestens um 1450, wahrscheinlich schon um 
1425 (Seufferts Annahme!) als vollendetes Ganze vorgelegen haben. Dass sie schon etwas älter ist, als die Emyich'sche Aufzeichnung (1472), scbliesst Zacher (a. a. O. S. 222) nicht mit Unrecht aus dem Grunde, weil bereits 1459 eine Bruderschaft in Frauenkirchen gestiftet wurde; die Sache muss aber noch schärfer gefasst werden. Die von Sauerborn veröffentlichten Ablassbriefe für Frauenkirchen (saec. XIV et XV) gestatten uns, mit hesonnener Kritik ausgedeutet, einen willkommenen Einblick in die allmähliche Entwicklung des Cultus unserer Maifelder Genovefa. Freilich begegnet in diesen Urkunden niemals der Name der Pfalzgräfin; aber man ist doch berechtigt, das, was dort über die zunehmende Frequenz der Processionen gesagt wird, die von den Bewohnern des Maifeldes nach Frauenkirchen unternommen wurden, mit der allmählichen Steigerung der Genovefa-Verebrung in Zusammenhang zu bringen.

Zu Anfang des 14. Jb. war die Legende sicher noch nicht ausgebildet: Erstlich wird in dem ältesten Ablassbrief von 1325 die Pfalzgräfin gar nicht erwähnt, obgleich derselbe das Datum des angeblichen Todestages Genovefas (2. April) trägt, und zweitens erhellt aus demselben Actenstiicke, dass die damaligen Frauenkirchener Processionen noch keine erhebliche waren. Dagegen findet sich in dem am 13. Mai 1449 zu Bacharach von dem päpstlichen Legaten Kardinal Joh. S. Angeli bewilligten Ablassbriefe (Sauerborn, S. 114 f.) schon eine deutliche Anspielung auf die regelmässige Abhaltung derartiger religiösen Aufzïge; diese Sitte besteht schon, nur soll der Zudrang der Andächtigen durch neue Indulgenzen noch g e ste i g e $\mathrm{t}$ werden. In dem Ablassbrief endlich, den Papst Pius II. am 17. April 1459 ausstellte (Sauerborn, S. $120 \mathrm{f}$.), wird ausdrücklich betont, wie die Bevölkerung jener Gegend eine besondere Verehrung für Frauenkirchen bege (,e t ad quam [capellam ... in Frauwenkirchen sitam] populus illarum partium magnum gerit devotionis affectum"). Sehr bezeichnend ist es itbrigens, dass gerade unsere Handschriften auf die betreffenden Ablassprivilegien anspielen, und zwar Emyich fol. XXIII nur ganz kurz, ausfübrlicher dagegen Johann von Andernach (bei Sauerborn, S. 94. 96. 98. 100. 102), sowie das Freher'sche Msc. (S. 22). Merkwürdig und bisher unaufgeklärt bleibt freilich die Thatsache, dass wir in dem ganzen Zeitraum zwischen 1327 und 1439 (vgl. Sauerborn, S. 119. 132 f.) gar nichts über die Kapelle erfahren. 
3. Gegen die Datirung der Entstehungszeit unserer Legende auf etwa 1325-1425 lässt sich, und zwar aus kunsthistorischen Gründen, nur ein einziger nennenswerther Einwand geltend machen, den sich sogar Brill hat entgehen lassen: In der Wiesenkirche zu Soest i. W., diesem herrlichen Kleinod der Gothik, findet sich ein Altartuch mit Stickereien (Jagdscene), deren Entstehungszeit Aldenkirchen (Die mittelalterliche Kunst in Soest, Winckelmann-Programm, Bonn 1875, S. 32) in den Anfang des 14. Jh. setzt. Luible (Die mittelalterliche Kunst in Westfalen, Leipzig 1853, S. 370) will in dieser Jagdscene eine Darstellung der Genovefa-Legende erblicken, bleibt aber jeden Beweis schuldig: Aldenkirchen dagegen (a. a. O. S. 29-33, vgl, dazu seine Tafel V) thut überzeugend dar, dass es sich um eine Darstellung der E i nh orn-Legende handelt; derselben Ansicht huldigt Nordboff (Anzeige der Aldenkirchen'schen Schrift, Pick'sche Monatsschrift II, S. 444 f. ; vgl. auch S. 442).

Leider ist mir das fragliche Altartuch aus $A$ u to p sie nicht bekannt, auch bedauere ich lebhaft, dass A. L u dorff s Bauund Kunstdenkmäler des $\mathrm{Kr}$ e is e s S oes t (darin natiirlich auch eine eingehende kunstgeschichtliche Würdigung der Wiesenkirche und ihres Altartuches!) noch nicht erschienen ist. Jene eingestickte Jagdscene bat jedenfalls mit der Genovefa-Sage gar nichts zu schaffen. Freilich, wäre es a nzw e if el haft, dass sich schon in einem aus dem beginnenden 14. Jh. stammenden Altartuch einer westfälis chen Kirche eine bildliche Darstellung unserer Legende vorfände, so müsste man ibre Entstehungszeit erheblich friber ansetzen, mindestens schon aufs 13. Jh. fixiren. Die Soester Jagdscene bezieht sich aber, wie gesagt, $\mathrm{n}$ i cht auf die Genovefa des Maifelảes. Denn erstens könnte man jene symbolischen Darstellungen $\mathrm{n}$ u $\mathrm{r}$ d a $\mathrm{n}$ mit der Pfalygräfin in Verbindung bringen, wenn Mutter und Kind nebst der Hirschkul unverke n n bar hervorträten. Das ist aber $\mathrm{n}$ i $\mathrm{cht}$ der Fall; denn sonst wäre jede Streitfrage zwischen Aldenkirchen und Lüble ausgeschlossen. Seuffert a. a. 0. S. 25 Anm. 6 stimnt dieser Beweisfïbrung zu: „Ferner hebt er (Görres) ... mit Recht hervor, dass das Altartuch ...., das aus dem Anfang des 14. Jh. sein soll, zum Beweis für das Alter der Legende nicht beigezogen werden kann; so lange sich Fachmänner streiten, ob darauf die Genorefaoder eine andere Geschichte dargestellt sei."

Zweitens: Bereits Aldenkirchen hat Lüble's Annahme aus 
dem durehaus zutreffenden Grunde verworfen, „weil ... keine der bekannten Versionen dieser Legende [der Genovefa-Sage] einem Künstler Anhaltspunkte für Anbringung von mit Krone und Mitra gezierten Jägern bietet" (a. a. O. S. 29). Drittens habe ich dargethan (oben S. 8ff.), dass die Genovefa-Sage zu Anfang des 14. Jhs. sogar in ihrer ursprïnglichen Heimath, im Maigau," erst noch in der frtihesten Kindheit war. Viertens: Noch um 1500 erscheint sie ausserhalb des Maifeldes gar nicht oder doch nur wenig verbreitet; denn sogar der doch aus der ziemlich nahen Moselgegend gebürtige Johannes Trithemius gedenkt der Sage nicht unter den Beispielen, welche er für die Macht Marias bei Gelegenheit des wunderthätigen Bildes zu Dittelbach anführt (vgl. Zacher's Art. „Genovefa" bei Ersch und Gruber a. a. O. S. 220 nebst Anm. 1 das.). Fünftens endlich gehören die notorisch auf die Auffindung der Pfalzgräfin beziiglichen bildlichen Darstellungen (Jagdscenen) am Tabernakel zur linken (Epistel-) Seite des Altars von Fra uen kirchen erst dem 17. Jb. an ${ }^{1}$ ). Die eingestickte Jagdscene des Soester Altartuches stammt also entweder aus dem beginnenden 14. Jh. - dann steht sie in keinerlei Beziehıng zur Maifelder Genovefa -, oder aber sie steht mit dem Schicksale der Pfalzgräfin in Zusammenhang; in diesem Falle muss man aber ibre Entstehungszeit zum Mindesten bis in's 17. Jh., d. i. bis zum Zeitalter des Jesuiten Cerisiers, hinausruicken, was indess den reich ausgestatteten Charakteren der Buchstaben und der Behandlung der Figuren und Ornamente widerspricht, die auf eine weit frühere Zeit hinweisen (s. Aldenkirchen a. a. O. S. 32).

Anhang. Beilage: Ueber die Namen Genorefa und Golo, sowie über den Kult der Pariser Genovefa in Maifeld.

Was die äusserst schwer etymologisch zu deutenden Namen Genovefa und Golo betrifft, so ist die Kritik iiber Heinrich Leo's Ableitung aus dem Keltischen - ihm bedeutet ersterer Name „die Frau von der Höhle“ und Golo „Heuchler"! - längst zur

1) Vgl. Lehfeldt, S. 385: „Altar [von Frauenkirchen], 1\%. Jahrhunderts, barock; zweigeschossig, nit gewundenen Säulen, mit Reliefs a s der Genovefas age ; überładen, geschmacklos. Sandstein, verstümmelt." 
Tagesordnung ibergegangen. Genovefa, wenigstens in zweiten Theile, ist unstreitig ein fränkischer Name: Greg. Tur. hist. Franc. IV c. 26, ed. W. Arndt, Mon. Germ. hist., Seriptor. rer. Merovingic., tom. I, pars I, Hannoverae 1884, S. 160-162 begegnet eine „Marcovefa“, eine Gemahlin des Königs Charibert von geringer Herkunft. Der Name - er lautet eigentlich Genoveifa ${ }^{1}$ ) - soll auf irgend eine Blume anspielen 2).

Dass übrigens der Name so ausserordentlich selten ist, braucht uns weiter nicht anzufechten. Was das Vorkommen dieses Namens in unserer Legende anbelangt, so giebt es dafür nur eine einzige, aber auch völlig ausreichende Erklärung, die nämlich, dass die Sage einfach den Namen der bekannten Schutzheiligen von Paris, der Zeitgenossin Chlodwigs, auf die Gemahlin des Pfalzgrafen übertragen hat.

Schon Seuffert (S. 20 ff.) hat Aehnliches vermuthet, freilich viel zu zaghaft. Aber ebenso entschieden als berechtigt tritt B riill, S. $17 \mathrm{f}$, für die gedachte These ein. Es ist freilich nur sehr wahrscheinlich, nicht durchaus gewiss, dass gerade die Laacher Benedictiner schon vor dem 14. Jh. die Pariser Genovefa besonders verehrt bätten. Es lässt sich aber urkundlich belegen, dass schon lange vor diesem Zeitpunkt der Cult der Pariser Heiligen wenigstens im nahen Andernach üppige Blüthen trieb. Es erhellt dies erstens aus Beyer, Mittelrhein. Urkundenbuch III, Nr. 1300, S. $941 \mathrm{f}$, wonach die Abtei Malmedy dem Kloster Namedy bei Andernach den Wald St. Genovefengereuth im Mai 1255 vererbpachtet. $\mathrm{Um}$ die Mitte des 13 . Jb. besass also die Abtei Malmedy schon sogenannte Genovefa-Guter in der Andernacher Gemarkung. Dies war aber nach einer weiteren, bisher noch ungedruckten Urkunde, die im 2. Bande der Görz'schen mittelrheinischen Regesten Verwerthung gefunden hat, schon zu Ende des 12. Jhs. der Fall. Nach dieser Urkunde ,resignirt im J. 1190 Heinrich von Molsberg an den Convent von Malmedy die ,advocatia

1) Zu Anfang von Greg. Tur. h. Fr. IV, 26 lautet der Name „Marcovefa", gegen Schluss (a. a. O. S. 162) "Marcoveifa".

2) Vgl. Brüll a. a. O. S. 4 Anm. 1: „Die etymologische Deutung des Namens Genovefa ist noch nicht gelungen, obwohl seine beiden Bestandtheile in einer ganzen Reihe von altdeutschen Namen vorliegen. Jakob Grimm, der das Wort dem Fränkischen zuweist [gewiss zutreffend; man beachte das soeben über ,Marcoveifa" Gesagte!], vermuthet darin ursprünglich den Namen einer Blume." 
super bonis S. Genovefae Andernaci', welche er von dem Abt dieses Klosters zu Leben trug und von ihm zu Afterlehen verliehen worden war, nachdem der Afterlehnsträger ebenfalls darauf verzichtet hatte." Dass in beiden Urkunden die Pariser Genovefa gemeint ist, unterliegt keinem $\mathrm{Zweifel.} \mathrm{In} \mathrm{der} \mathrm{zuerst} \mathrm{ge-}$ nannten Urkunde vom Mai 1255 kommt auch eine „capella S. Genovefa Andernacensis" vor ${ }^{1}$ ). Durchaus zutreffend urtheilt Briull S. 16 über den Cult der Pariser Genovefa speciell in Andernach: „Zwar ist es ein Irrthum, wenn die Pfarrkirche von Andernach hin und wieder als Genovefakirche bezeichnet wird ${ }^{2}$ ). Nur eine Kapelle war hier dem Andenken dieser Heiligen geweiht. .. Eine solche ist noch vorbanden, aber in die umfänglichen Gebäude der Weissheimer'schen Malzfabrik am Merowingerplatze ein bezogen (S. 16, Anm. 3)... Sie gebörte zur Probstei St. Genovefa " u. s. w. Weiter betont Brîll a. a. O. S. 16 mit Fug, dass gganz nahe bei der Abtei ... Laach, im alten Flecken Obermendig, noch bis auf den hentigen Tag die hl. Genovefa von Paris als Schutzheilige verebrt wird, und ibr die dortige Pfarrkirche ehrwürdigsten Alters geweiht ist" ${ }^{3}$ ).

Die Maifelder Genovefa wird in der dortigen Gegend fast allgemein als Heilige verehrt. Das kann man mit Brüll a. a. $O$. S. 16 aus dem Umstand erklären, dass die Sage eben den Namen der Pariser Heiligen anf die Gemahlin Siegfrieds übertragen hat. Uebrigens hat die katbolische Kirche es glücklich vermieden, die Heldin der Sage in ihr Calendarium aufzunehmen: Dass Baronius sic seinem zuerst 1592 gedruckten „Marryrologium Romanum“ s. 2. April nicht einverleibt hat, kann nicht Wunder nehmen; denn damals, ubberhaupt vor Cerisiers, war die legendarische Genovefa ausserhalb des Maifeldes fast völlig unbekannt. Dagegen haben die älteren Bollaudisten (Acta Sanct. s. 2. April. p. 57), denen das Freher'sche Ms. und auch schon Cerisiers' Buch mit seinen willkiurlichen Erfindungen und Zuthaten zur Verfügung stand, in bewusster

1) Auf diese bedeutsame Urkunde von Mai 1255 wird weiter unten (S. 25. 38 f.) in anderem Zusammenhang zurückzukommen sein.

2) Lehfeldt a. a. Q. S. 354 bezeichnet die Andernacher Pfarrkirche als „Liebfrauen(Genovefa)-Kirche". Ausführliches über die Geschichte und das Innere dieses interessanten Gotteshauses ebenda S. 354-361.

3) Näheres über diese Kirche bei Lehfeldt a. a. O. S. $433 \mathrm{f}$. (,Ohermendig ... Kirche ..., h. Genovefa"). 
klarer Kritik es abgelebnt, eine offenbar sagenhafte Persönlichkeit als Heilige anzuerkennen.

Brîll a. a. 0. S. 16 hat Recht, wenn er die Etymologie des Namens Golo nach wie vor für zweifelhaft hält. Seuffert (S.23 und Anm. 4 das.) will in "Golo" einen Kosenamen sehen und, bringt ibn mit Gottfried (von Calw) in Verbindung. Indess das ist immerhin nur eine Vermuthung, wenn es auch nahe liegt, insofern es als ausgemacht gelten darf, dass Pfalzgraf Siegfried, der zweite Stifter von Laach, der Held unserer Sage geworden ist, auch den Statthalter dieses geschichtlichen Siegfried mit dem Burgvogt des sagenhaften Pfalzgrafen in Zusammenhang zu bringen.

Maler (Friedrich) Müller in seinem Schauspiel „Golo und Genovefa" (= Werke III, Heidelberg 1825) und F. J. Kiefer a. a. O. S. $103 \mathrm{f}$. nennen Golo einen Ritter vom Drachenfels, indess im schroffsten Widerspruch mit den älteren Handschriften der Sage und sogar mit Cerisiers!

\section{Die echten und die falschen Stätten der Genovefa-Sage.}

\section{A. Die e chten Lokalitäten.}

Die älteren Handschriften saec. XV - diese bilden natürlich, weil allein die unverfälschte Quelle unserer Legende repräsentirend, bei Entscheidung der vorliegenden Streitfragen die einzig massgebende Instanz - bringen die Legende in die engste Verbindung mit der Kapelle Frauenkirchen, und demgemäss werden alle Lokalitäten in die Nähe von Mayen und des Laacher Sees gertickt. Es kommen da folgende Oertlichkeiten in Betracht: 1. Der Hochsimmer bei Mayen bezw. eine angeblich auf diesem Bergkegel gelegene Burg. 2. Ochtendung. 3. Wernerseck. 4. Der Laacher See. 5. Die Kapelle Frauenkirchen. Alle diese Stätten bestehen wirklich; bloss die unter 1. erwähnte Burg erscheint geschichtlich nicht nachweisbar.

1. a) Die Handschriften berichten übereinstimmend, dass Pfalzgraf Siegfried seiner Gemahlin für die Dauer seiner Abwesenheit (im Kreuzzug gegen die syrischen Sarrazenen) ein im Maifeld gelegenes festes Schloss zum Aufenthalt anwies; Emyich fügt hinzu, dass die Burg auf einem hohen Berge lag. Der Name des Castells 
variirt etwas: Die Handschriften bieten die Bezeichnungen „Palatiolum Soemerium", „,eastrum Symern“, „castrum Semmer", „mons Seemer", nennen also nicht die Stadt Mayen selbst, sondern nur das Maifeld, den Maigau, wozu Mayen gehört' ${ }^{1}$, jedenfalls denken aber Sauerborn (Geschichte der Pfalzgräfin Genovefa S. 62, Anm. 2) und Zacher (a.a. O. S. 220) hier mit Recht an den nordwestlich von Mayen gelegenen Berg Hochsimmer. „Nordwestlich von der Stadt (Mayen) erhebt sich der Hochsimmer mehr als 1800 Fuss tiber dem Meeresspiegel, ein hoher Schlackenkegel, bei welchem der westliche Gebirgszug beginnt" (Bärsch, Eiflia illustrata Bd. III, 1. Abtheil., 2. Abschn., S. 84 f.). „Der Marktplatz zu Mayen ... liegt nach der alten Messung 735 rhein. Fuss über dem Meeresspiegel. Nach derselben Messung ist der Hochsimmer als böchster Punkt des Kreises Mayen anf 1888 Fuss angegeben. Nach der neueren Höhenkarte von v. Dechen aber haben die beiden höchsten Spitzen des Kreises, der Hochsimmer und der Hochbermel, gleiche Höhe, nämlich 574 Meter, was erst 1828 Fuss ergibt" ${ }^{2}$ ).

Die Legende verlegt die Burg Siegfrieds nach jenem Bergkegel; die Namensähnlichkeit ist unverkennbar. Aehnlich wie die beutige Burg Rheinstein, dieses Schmuckkästchen des Mittelubeins, ursprünglich (im 13. Jahrb.) Rhe in bodenstein nach dem Theile des rheinischen Sehiefergebirges, worauf sie lag, benannt wurde, heisst das Genovefa-Heim nach dem betreffenden Bergkegel

1) Die betreffende Stelle im Hontheim'schen Msc. (s. Hontheim, Hist. dipl. Trevir. I, S. 26 f.): „mandavit [sc. Sifridus], ut . . Genovefa consisteret in Palatiolo Soemerio, quod constructum est in quodam pago Meynfeldensi.“ Freher (Hist. palat. S. 18): „... precepit Palatinus ... ipsam in pago Meifeldensi in castro Symern morari" etc. Johann von Andernach (bei Sauerborn a. a. O. S. 60 f.): ,... praecepit Palatinus ... ipsam in pago Meynfeldensi in castro Semmer morari" etc. Emyich (fol. IVa): „Tunc enim erat in Meynfeldensi pago castruin quoddam maximo cinctum muro forte valde atque humana arte vix expugnabile monte in alto atque conspicuo Seemer ex vocabulo dictum vetustate iam neglectum atque dirutum. Hoc enim tam feracis terre ubertate quam loci amenitate serenioris aeris puritate iocundum erat: illa vero terra grata planicie et interiectis collibus ac montibus circumflexis aprica est pariter et humanis apta usibus."

2) Aus einem mir von Herrn Bürgermeister Schäfer zu Mayen freundlichst zur Verfügung gestellten Schreiben des Herm Buchdruckereibesitzers Gerhard Hipp zu Mayen vom 18. Juli 1897. 
laut der ältesten und genauesten Form der Legende selbst der Hochsimmer oder allenfalls, wie Simrock will, Hohensimmern ${ }^{1}$; alle übrigen Bezeichnungen beruhen auf Willkür. Unerfindlich ist z. B., wie Hontheim (Hist. dipl. Trevir. I, 27) dazu kommt, den Hochsimmer in ,Sonnenberg" (!) umzutaufen. Der wackere Jugendschriftsteller Christo ph Schmid gefällt sich in seiner "Genovefa" in folgender etymologischen Spielerei: „Siegfriedsburg $=$ Siefriedsheim $=$ Siegmern = Simmern!! Endlich stiitzt sich die Benennung "Friedrichsburg“" in dem bei Jung and Alt so beliebten Puppenspiel ,Genoveva. Trauerspiel zum Dutlaache in 5 Akten" lediglich auf die Autorität des Kölner Hänneschen-Theaters!

b) Die sich jetzt darbietende Frage: Hat wirklich eine Burg Hohensimmern auf dem gleichnamigen Berge existirt? mit Hontheim I, 27 bloss auf Grund der Erwäbnung in den GenovefaHandschriften, also in Documenten von immerhin verdächtiger Zuverlässigkeit, zu bejahen, ist unkritisch. Bis jetzt wenigstens lässt sich keine einzige Urkunde oder sonst ein authentisches Actenstuck nachweisen, worin etwa Ritter oder Burgmannen von Hohensimmern vorkämen. Wie Hontheim, so treten auch Tolner (in seiner Geschichte der Pfalzgrafen bei Rhein) und P. Kupp O. s. B. fiir die Geschichtlichkeit der fraglichen Burg ein. Ersterer stellt die mebr als kiihne Bebauptung auf, das Siegfriedsheim sei, wie die meisten [rheinischen] Paläste, einst durch die Normannen, also schon etwa im 9. Jh., zerstört worden. Kupp will gar noch zu Ende des vorigen Jahrbunderts in Gesellschaft noch eines Ordensbruders die "Rudera" der Burg sich angesehen haben. Sehr bedeutend können aber diese Trümmer vergangener Herrlichkeit nicht gewesen sein; denn Matthias Emyich theilt mit, das Schloss sei zn seiner Zeit, d. i. schon im J. 1472, „durch's Alter vernachlässigt und zerstört gewesen“. „Was ... von älteren Gewäbrsmännern, zuletzt von Kupp, behauptet wird von den Rudera eines solchen Bauwerkes auf der Bergeshöhe, die sie noch mit eigenen Augen gesehen haben wollen, steht mit dem späteren und jetzigen Befund so sehr in Widerspruch, dass man eine Selbsttäuschung dieser Autoren annehmen darf. ... So werden wir die Burg auf

1) Nicht mit Unrecht meint Wirtgen, Eifel ${ }^{1}$. Das Nette- und Brohlthal und Laach, Bonn 1864, S. 18: „Diese alte Burg [das Siegfriedsheim] mag wohl Hobensymern gebeissen haben". 
der Höhe des Simmer s e in er [Emyich's] Phantasie und seinem Wortschwall auf die Rechnung setzen" (Brill S. 8).

Aus inneren Grïnden, d. h. durch den Hinweis anf die natiirliche Beschaffenheit des Bergkegels Hochsimmer selber, thut Julius Wegeler („Zur Genovefa-Sage“, Pick'sche Monatsschrift Jahrg. III, 1877, H. 7,9, S. 461 f.) unwiderleglich dar, dass das fragliche Kastell dem Bereiche des Mythus angehört, niemals existirt haben kann: „Die Spitze des Hochsimmer wird von einem halbkreisförmigen, gegen Mayen hin offenen Krater gebildet. ... In einen solchen oder auch nur auf den Wall eines solchen ... wird doch wohl nie eine Burg gebaut worden sein. ... Auch wiisste ich keine zweite Burg zu nennen, die auch nur in die Nähe eines Kraters, vielweniger in oder auf diesen selbst gebaut worden sei. ... Nun bildet der Hochsimmer einen ziemlich platt abgestumpften Kegel, der keine Spur von Einschnitten zeigt, wie sie etwa von Wegen, Gräben u. s. w. herzurühren pflegen. ... Ich selbst fand im J. 1832, als ich nicht ohne Schwierigkeit den Berg erstiegen, keine Spur von Mauerresten, keine umherliegenden Steine, die etwa zu einem Mauerwerk gehört hätten, noch fanden sich solche in dem benachbarten Dorfe Ettringen.... Uebrigens wurde der Hochsimmer nur selten erstiegen, er bildete kein Ziel geselliger Excursionen, keine Wirthschaft war in der Nähe -, und so sollte man fast den Besuch des P. Kupp und seine Beobachtung bei demselben bezweifeln. Reihen wir hieran, dass des Hochsimmer'schen Schlosses nur in der Genovefa-Sage Erwähnung geschieht ..., so muss man der Ansicht des Herrn Görres durchaus beistimmen, dass die Annahme einer Burg auf dem Hochsimmer in das Reich der Mythen gehört."

Zutreffend leugnet auch Wirtgen a. a. O. S. 18 die Existenz einer Burg auf dem Hochsimmer: .. „Auf dem [Mayen] benachbarten Hochsimmer, diesem nuächtigen Vulkane, is t $\mathrm{k}$ e in e Spur einer Burg; a u ch war auf demselben kein Ra um daf ì r."

2. $0 \mathrm{cht}$ e $\mathrm{n} d \mathrm{ug}$ ist heute ein ansehnliches Dorf im Maifeld und liegt an der Nette zwischen Mayen und Koblenz, „kaum eine Stunde östlich von der Frauenkirche" (Briill a. a. O. S. 8), „13 km ostnordöstlich von Mayen" (Lehfeldt a. a. O. S. 434).

Der Umstand, dass die Handschriften den angeblichen Trierschen Erzbischof Hildulf im Palatium zu Ochtendung residiren 
lassen, berechtigt uns keineswegs, mit Hontheim I, 26 zu vermuthen, die Frankenkönige hätten schon in alter Zeit eine Pfalz in jenem Dorfe besessen: davon weiss die beglaubigte Geschichte nichts zu erzählen; ,... es stützt sich diese Vermuthung, wie es scheint, lediglich auf die hier in Rede stehenden Ueberlieferungen der Genovefalegende selbst" (Brïll a. a. O. S. 8 f.). Ochtendung kommt nämlich, und zwar als ,ofdemodinge", zuerst in einer Urkunde vom 10. Juni 963 vor (Beyer, Mittelrhein. Urkundenbuch I, S. $272 \mathrm{f}$., Nr. 213). Jene Notiz über das Residiren Hildulfs zu Ochtendung beweist eben nur so viel, dass die Sage bemüht ist, alle Lokalitäten in die Nähe von Frauenkirchen zu rücken. Hildulf $\mathrm{m} \mathrm{uss}$ ja in der Nähe von Hohensimmern residiren, damit er, der am 5. Januar unmittelbar nach der Wiederauffindung der Pfalzgräfin durch Boten um kirchliche Einweihung der betreffenden Stätte im Walde ersucht wird, schon am folgenden Tage, dem Dreikönigs-Feste, den für eine künftige Kapelle bestimmten Raum, die Stelle, wo Siegfried seine Gemablin wiedergefunden, consecriren kann $\left.{ }^{1}\right)$.

3. Auch die Angabe von $\mathrm{Mathi}$ a $\mathrm{Emyich}$, wonach die Residenz der Trierschen Erzbischöfe nach Werners e ck verlegt wurde, beweist, wie eifrig unsere Legende bemuht ist, alle nur irgendwie auf die Geschichte Genovefas bezïglichen Stätten im Maifeld zusammenzudrängen; denn auch die hochragende Burg Wernerseck, „noch heute als malerische Ruine eine Zierde der Gegend" (Brüll S. 9), liegt im Maifeld, etwa $1 / 2$ Stunde von Ochtendung, nahe bei Saffig, auf einem Felsen am linken Netteufer. ... Von den Trümmern hat man eine herrliche Aussicht (Bälsch a. a. O. S. 55). Der Triersche Erzbischof Werner von Falkenstein hat diese Burg (1400-1402) erbaut. Das Schloss gehört also erst der späteren Zeit der Entstehungsgeschichte unserer Legende an und fand doch sofort Verwerthung ${ }^{2}$ ).

1) Näheres über Ochtendung bei Wirtgen a. a. O. S. $21 \mathrm{f}$. und Lehfeldt, S. 434. Letzterer meint S. 448: „Ochtendung. Palast ... von den Trierschen Erzbischöfen, u. a. Hildulph [sic!] . . bewohnt, bis Wernerseck gebaut wurde." Eine ungeheuerliche These, wofür nur der unkritische Sanerborn, ... Genovefa ... S.54 angeführt wird, und die bloss in den Genovefa-Hand schriften vorkommt!

2) Das spärliche urkundliche Material - Günther und Lacomblet versagen hier völlig! - bei Bärsch a. a. O. S. 55. Erläuterungsschriften 
„So wenig nun auch die Geschichte und Urkunden iberWernerseck zu sagen wissen, so lebhaft beschäftigt sich die Phantasie der Umgebung mit derselben. ... Die Burg war nach der Meinung der Umwohner der Sitz der T e mpel herren, welche. unter Beihuilfe des Teufels ungeheuere Schätze hier aufhäuften"... (Wirtgen a. a. O. S. 35 f.). Dass aber dieser Sage nicht der geringste geschichtliche Kern zu Grunde liegen $\mathrm{kann}$, erhellt aus. der Entstehungszeit Wernersecks, erst 1400/2, während der Untergang des Tempelordens schon ein Jahrhundert vorber erfolgt war(durch Philipp IV. und Clemens V. 1305 ff.).

4. Der $\mathrm{L}$ a a c b e r S e e kommt ebenfalls schon in der ältesten. Form der Legende vor; denn nach sämmtlichen Handschriften hatte Golo ursprïnglich vor, die vom überlisteten Grafen verurtheilte Genovefa „im See" („in laca") ertränken zu lassen.

5. Ueber die $\mathrm{Ka} \mathrm{pelle} \mathrm{Frauenkirchen} \mathrm{ist} \mathrm{bereits} \mathrm{ober}$ (S. 10-13) in anderem Zusammenhang das Erforderliche gesagt worden.

6. Unter die richtigen urwïchsigen Genovefa-Ueberlieferungen. bezw. Lokalisirungen des Maifeldes rechne ich schliesslich aucl folgende, obgleich sie nur mittelbar durch die älteste Form der fraglichen Sage bestätigt wird: Ein in der Nähe von Ochtendung, also auch von Frauenkirchen, wo Genovefa wiederaufgefundell: wurde und Golo sein barbarisches Todesurtheil empfing, befindlicher kleiner Walddistrikt heisst nämlich bis auf den heutigen Tag (zum mindesten seit dem 15., wahrscheinlich schon seit dem 14. Jh.) im Volksmund "Golobiisch"; hier soll also an dem Verbrecher die grausame Todesstrafe vollstreckt worden sein ${ }^{1}$ ).

Dass diese Lokalisirung noch jetzt sehr beliebt ist, erhellt aus. einem mir gütigst zur Verfügung gestellten Schreiben des Herrn Ra demacher (bis 1891 Kreissecretär zu Mayen, seitdem zu Koblenz) vom 7. Juli 1897, wo es heisst: „Im Bann der Gemeinde Cottenheim oder Thür an der Strasse von Mayen nach der Frauen(Genovefa)kirche bei Niedermendig liegt ein Distrikt, der den.

ausser Bärsch a. a. O.: Wirtgen a. a. 0. S. 34-37 mit lithographirter Ansicht, zwischen S. 32 und 33 und zumal Lehfeldt a. a. 0. S. $443 \mathrm{f}$.

1) Vgl. Fr. Menk, Sagen der Mosel, Koblenz 1840, S. 186 Anm. und Sauerborn a. a. O. S. 90 Anm. 2. 
Namen ,im Geviertelt ${ }^{6} \ldots$ führt. Wie das Volk erzählt, soll der Name daher rübren, dass dort der böse Golo geviertheilt wurde."

Britll (S. 16 Anm. 2) scheint, sich gegenüber der urwüchsigen „Golobüsch"-Ueberlieferung allzu zweifelhaft zu verhalten: „... Es ¡st ... nichts Verlässiges tiber das Alter dieser Flurbezeichnung zu ermitteln, und man wird darum am ehesten dafür eine Anlehnung an die Legende annehmen."

B. Diefalschen Stätten der Genovefa-Legende.

1. Brüll a. a. O. S. 8 meint: „... Der Streit ist auch nicht erledigt mit dem Nachweis, dass auf der Höhe des Simmer eine Burg nicht gestanden hat. ... Noch heute finden wir an der westlichen Abdachung des Hochsimmer im lieblichen Thale der Nette Schloss Bürresheim ...., das auf ein sehr ehrwürdiges Alter zuriickblickt. Sollte dies nicht den Anhalt dafür geben, an welcher Stelle sich der Erzähler seine Siegfriedsburg gedacht hat? Jedenfalls hindert die Ueberlieferung nicht, diese Lage für das castru $\mathrm{m}$ S e m mer anzunehmen."

Briill hat insofern Recht, als Schloss Biir r e h e i m nicht bloss in Maifeld liegt, sondern sogar noch in etwa mit dem $\mathrm{Hochsimmer}$ zusammenhängt. Ja ausser dem von der Sage auf jenem Bergkegel gedachten Kastell kann bei unserer Streitfrage nur Bürresheim tiberbaupt in engere Wahl kommen. Ist doch auch an seinem ehrwürdigen Alter nicht zu zweifeln: „Es war das Stammhaus eines alten Geschlechts, von welchem Eberhardus de Bürgenesheim schon 1158, Ewardus de Burgnescein 1164, Ernestus de Burgisheim 1206, Henno de Burensheym, dictus de Dura und sein Bruder Heinrieh 1320, Frydrich von Burensheim 1341 in Urkunden vorkommen" " . s. w. ${ }^{1}$ ). Aber anderseits lässt sich das Höhenverbältniss von Bürresheim mit dem zum Hochsimmer mit seinen mindestens 1828 Fuss über dem Meeresspiegel gar nicht

1) In den Urkunden kommen vor: de Burgenesheim ..., Everardus et filii eius Rodulfus et Henricus frater eius de Burensheim 1173 bis 1183 und 1186 (Beyer II, Nr. 20, S. 57 f., Nr. 62, S. 103 f., Nr. 85, S. 123). Ebenda III, Nr. 1168, S. 810: "de Burgisheim Nicolaus miles 125:". Vgl. auch Hontheim, Hist. dipl. Trevir. I, S. 586. Erläuterungsschriften: Bärsch a. a. O. S. 180, Wegeler, Laach, S. 89, Wirtgen, Nette und Brohlthal-Eifel 1, Bonn 1864, S. 90 f. mit lithographirter Ansicht der Burg (gleich nach dem Vorwort) und vor Allem Paul Lehfeldt, S. 372-375. 
vergleichen. „... Bürresheim liegt auf einem hohen, von der Nette ... umflossenen $\mathrm{H}$ ü $\mathrm{gel}$, in einem schönen, von Waldeshöhen umgebenen Thale" (Bärsch a. a. O.; vgl. auch die lithographirte Ansicht der Burg bei Wirtgen a. a. 0 . gleich nach dem Vorwort) - , und seine urkundlichen Benennungen, selbst in der auch von Brüll a. a. O. erwähnten ältesten Form (Bürgenesheim), haben doch mit „Semmer", „Seemer" u.s.w. gar nichts zu thun. Es muss also mit Wegeler's (a. a. O. S. 462) Entscheidung sein Bewenden haben: ,Die Annahme, dass an irgend einer andern Stelle des Maifeldes [als auf dem Hochsimmer] etwa eine andere Burg gestanden habe, wird durch nichts gerechtfertigt, während die Burg auf dem Hochsimmer der bestgewählte, am meisten in die Augen springende, der dichterisch schönste Punkt war, der nur möglich."

2. Wie die Brüll'sche These, muss auch die Mayener Lokaltradition nach den bisherigen Erörterungen als ein seltsames Gemisch von Echtem und Falschem (im Sinne der ursprünglichen Sage) erscheinen. Auch dort existirt nämlich ein sogenanntes Genovefa-Haus oder eine Genovefa-Burg, noch unlängst eine Bierbrauerei (!!). Diese Tradition ist echt, insofern sie die Sage wenigstens überhaupt nach dem Maifeld verlegt, ist aber insofern unberechtigt, als sie die Burg der Pfalzgräfin im Widerspruch mit den älteren Handschriften nicht ausserhalb von Mayen nach dem Hochsimmer, sondern in das Innere der Metropole des Maifeldes versetzt; zudem kann das Höhenverbältniss der angeblichen Mayener Genovefaburg mit dem des Hochsimmer durchaus nicht den Vergleich aushalten ${ }^{1}$ ). Zutreffend bemerkt Brüll a. a. O. S. 7: „Die

1) „Der Marktplatz zu Mayen, an dessen Südspitze die Burg sich anschliesst, liegt nach der alten Messung 735 rhein. Fuss über dem Meeresspiegel. ... Vor der Burg nun liegt der äussere Hof, der alte Zwinger oder Viehhof, ein ziemliches Stück höher als die Stadtmauer, wie man von der Brücke an der Fallpforte deutlich sieht. Dieser Hof muss aber früher noch höher gelegen haben; denn besonders am Hauptthurme zeigt sich deutlich, dass er später abgetragen und dadurch das Fundament des Thurmes blossgelegt worden ist. Jedenfalls ist dieses geschehen, um die später als die innere Burg, vielleicht sogar später als die Stadtmauer (dann also 1709) erbaute Brücke erreichen zu können. Von diesem Hofe nun führt eine steinerne Treppe von $34 \mathrm{Stufen}$, jede von $5 \frac{1}{2}$ Zoll, $\mathrm{nach}$ dem innern Hofe, der eigentlichen Burg, die also ca. 30 Fuss über dem äussern Thorbofe und 70 bis 80 Fuss über dem Marktplatze liegt" (Aus dem Schreiben des Herrn Buchdruckereibesitzers Gerhard Hipp zu Mayen vom 18. Juli 1897). 
Siegfriedsburg in der Stadt Mayen zu suchen, gibt die Ueberlieferung ebensowenig Anlass; trotz seiner nahen Berührung mit dem Schauplatze der Ueberlieferung kommt Mayen selbst darin nicht vor. Lokale Traditionen, die auf das Gegentheil schliessen lassen, sind gewiss jüngeren Ursprungs, ohne dass sich vorderhand uiber ihre Entstehung genauerer Aufschluss geben lässt" ${ }^{61}$ ).

3. Nach einer im Koblenzer Staatsarchiv berubenden, Beyer, Vittelrhein. Urkundenbuch III, Nr. 1300, S. 941 f. abgedruckten Urkunde ,vererbpachtet die Abtei Malmedy dem Kloster Namedy bei Andernach den Wald St. Genovefengereubt (... silvam quandam, que communiter S. Genovefe gereuht [natürlich nicht $=$ Genovefas Rube, sondern = Ausgerodeter, urbar gemachter Genovefa-Wald, von dem bekannten roden, ausroden!] appellatur).

Liegt nun in diesem "S. Genovefe gereuht" (in der Andernacher Gemarkung) anch eine so urwüchsige Genovefa-Ueberlieferung des Maifeldes vor, wie in "Golobuisch"? Diese Frage wäre zu bejahen, falls das Actenstück etwa erst frïhestens aus dem 15. Jh. stammt. Da es aber bereits vom Mai 1255 datirt ist, und anderseits sich unsere Legende erst zwischen 1325 und 1425 ausgebildet hat, so bezieht sich jener Andernacher Walddistrikt unstreitig auf die Pariser Genovefa (s. oben S. 15 f.).

4. Was ferner die Vermuthung anbelangt, das längst verschwundene, bereits gegen Ende des 13. Jh. zerstörte S chloss $\mathrm{L}$ a a c h sei mit der Siegfriedsburg identisch, so lautet diese Hypothese auf den ersten Blick sogar nicht ganz unwahrscheinlich, insofern das erwähnte Castell überhaupt dem Bereiche der unzweifelhaft echten Lokalitäten unserer Legende angehört, ist aber gleichwohl abzuweisen: Schloss Laach, die zeitweilige Residenz der Pfalzgrafen bei Rhein (im 11. und 12. Jb.; s. unten S. 26), lag unmittelbar am Laacher See, unweit der gleichnamigen Abtei in der Hochebene ${ }^{2}$ ), wäbrend das Siegfriedsheim sich in stattlicher unmittelbarer Höbe aufgethürmt haben soll.

1) Näheres üler die sog. Mayener Genovefa-Burg auch bei Wirtgen a. a. 0. S. $17 \mathrm{f}$. und zumal Lehfeldt $\mathrm{S} .411 \mathrm{f}$. Wirtgen a. a. 0 . und Fr. Menk, Sagen der Mosel, Coblenz 1840, S.183, 258, Anm. 81 huldigen obigen Ausführungen zufolge mit Unrecht der Mayener Lokaltradition.

2) Vgl. Paul Richter, Die alte Pfalz am Laacher See, Korrespondenzblatt der Westdeutschen Zeitschrift für Geschichte und Kunst, Jahrg. XIII 1894, Nr. 8, Heft 112, S. 167-171. 
5. Da die ältesten Handschriften, die einzig berechtigte Quelle der Sage, sämmtliche Stätten derselben ins Ma ifeld verlegen, sa hat man weiter mit Sauerborn a. a. O. S. 63 Anm. 2, Bernh. Seuffert a. a. 0. S. 80 und Briill a. a. 0. S. 7 die Annahme des Jugendschriftstellers Christoph Schmid abzulehnen, der in seiner "Genovefa" das Siegfriedsschloss nach dem Hunsrück in die Kreisstadt Simmern (Rgbz. Koblenz; vgl. Lehfeldt a. a. 0. S. $672 \mathrm{ff}$.) bezw. in deren Nähe verlegt.

Diese Fixirung, der meines Wissens nicht einmal eine späte Lokalüberlieferung zur Seite steht - in der Thatsache, dass in dem alten Flecken Castellaun (eine Stunde von Simmern) vier Jahre hindurch (1862-66) ein Puppentheater die „Genovefa" spielte, ist doch bloss eine Wirkung der erst durch Schmid begründeten Tradition zu erkennen (s. Seuffert S. 80 und Brill S. 7 nebst Anm. 1 das.) -, berubt nur auf einer zufälligen Aehnlichkeit der Namen Hohensimmern und Simmern. Zu treffend bemerkt Brüll a. a. O.: „Nur ... Christoph Schmid verlegte seine Siegfriedsburg Siegmern in die Kreisstadt Simmern auf dem Hunsrück, weil er den Stoff zu seiner Genovefa aus solchen Quellen entnahm, welche den Zusammenhang der Ueberlieferung mit der Kapelle Frauenkirchen und dem Laacher See a ufgeben."

6. Jos. Bajovar im Eingang seiner ansprechenden Novelle "Alpenrosen und Gentianen" (,Ueber Land und Meer" 1886 Nr. 48, S. 1029) meint: „Von dieser Burg [Kochem a. d. Mosel] blickte einst Pfalzgraf Siegfried zu Thal, der Gemahl der frommen Genovefa." Ich erwidere: Auch diese Lokalisirung unserer Legende ist unzulässig, weil nur durch die romantische Lage der jetzt ebenso prächtig als pietätvoll restaurirten Burg Kochem veranlasst; Folgendes meine Gründe:

a) In der Thatsache, dass die Pfalzgrafen bei Rhein im 11. und 12. Jahrhundert bis 1197, bis zu dem Zeitpunkt, wo der Schwerpunkt der pfalzgräflichen Macht nicht mehr im Trier'schen, sondern bereits in Heidelberg ist, öfter zu Kochem Hof gehalten haben, liegt kein Beweis zu Gunsten des Bajovar'schen Satzes; denn die rheinischen Pfalzgrafen haben im gedachten Zeitraum abwechselnd zu Kochem, Tomburg, Stahleck, Schloss Laach residirt.

b) Die Lokalisirung unsers Novellisten widerstreitet der ursprünglichen Form der Legende: Kochem gehört nicht zum Maifeld. c) Die Bajovar'sche These steht sogar mit der spätern Ent- 
wicklung unserer Sage durch und seit Cerisiers im Widerspruch, insofern ibr auch nicht die leiseste Kochemer Lokaltradition zur Seite steht ${ }^{1}$.

7. Auch das Städtchen Pfalzel bei Trier hat gar kein Recht, mit seinem vorgeblichen Genovefa- und Golohaus, sowie mit der beim benachbarten Ehrang gelegenen sogenannten Genovefahöhle als Heerd der ursprünglichen Legende gelten zu wollen ${ }^{2}$ ). Nit Fug hat demnach schon Zacher (a. a. O. S. 222, Anm. 20) angenommen, dass die Pfalzeler Lokaltradition nicht über das 17. Jahrhundert, das Zeitalter des Jesuiten Cerisiers, hinausragt, und nicht minder richtig meint neuerdings Brüll (a. a. O. S. 7): „Noch weniger [als die Mayener Lokaltradition u. s. w.] mit der Ueberlieferung in Verbindung zu bringen sind die Ansprüche des Städtchens Pfalzel bei Trier mit seiner Genovefahöhle und dem Golohaus." Zutreffend ist auch folgende Vermuthung, die mir C. Schömann, der frithere Triersche Stadtbibliothekar, schon vor zwei Jahrzehnten brieflich übermittelt hat: „Ich glanbe, diese sonderbare Lokalisirung rerdankt ihren Ursprung einem lokalpatriotischen Geistlichen jüngerer Zeit, der bei dem Pfalzgrafen nur an das Städtchen Pfalzel dachte, und dem die bekannte Höhle im gleichnamigen Walde wohl geeignet schien, sie zum Aufenthaltsort Genovefas und

1) Vgl. Lehfeldt S. $240 \mathrm{ff}$. und zumal $243 \mathrm{f}$.

Ich benutze diese Gelegenheit, das fleissig gearbeitete, auf umsichtiger Benutzung des gesammten gedruckten Quellenmaterials, zumal des mittelrheinischen Urkundenbuches von Beyer-Eltester, basirende Schriftchen von Nicolaus Pauly, Stadt und Burg Cochem, Cochem 1883, 135 S., angelegentlich allen Freunden der rheinischen Provinzial- und Culturgeschichte zu empfehlen. - Weder Pauly noch Lehfeldt kennen eine Kochemer Genovefa-Tradition.

2) N. Hocker, Des Mosellandes Geschichten, Sagen und Legenden, Trier 1852, S. 150 nebst Anm. ist der eifrigste Vertreter dies er Lokalisirung: Er geht so weit, den ersten Vers des bekannten Simrock'schen GenovefaGedichtes (,Hohensimmern war die Veste, wo Pfalzgraf Siegfried sass") in folgender Form zu verballhornen: „Zu Pfalzel stand die Vestec. u. s. w. Von köstlicher Naivetät zeugt Hocker's Begründung seiner willkürlichen Aenderung: „Der geehrte Herr Verfasser wird diese kleine Aenderung. entschuldigen. Verschiedene Schriftsteller [!] versetzen die herrliche Legende von Siegfried und Genovefa nach Pfalzel, auch die Volkssage weist ihr den Platz dort an [??]. Um aber das schöne Gedicht in unsere Sammlung aufnehmen zu können, mussten [!] wir den Hochsimmerberg mit Pfalzel vertauschen" [sic!]. 
ihres Schmerzenreich zu stempeln." Bärsch, Eiflia illustrata Bd. III, Abth. 2, Abschn. 1, S. 488 erwähnt das „Genovefenhaus zu Pfalzel" und bemerkt über die erwähnte Höhle (S. 489) Folgendes: „In einem bohen Sandsteinfelsen tief im Pfalzeler Walde liegt eine grosse Höhle, welche die Bruderhöhle, auch der Altarstein genannt wird. ... Steininger vermuthet, dass diese Höhle ursprünglich eine Druidenhöhle gewesen sei."

Ich glaube, zur Verbreitung der Pfalzeler Lokaltradition hat der Romantiker Maler (Friedrich) Müller viel beigetragen, der in „Golo und Genovefa. Ein Schauspiel in fünf Aufzügen (=Werke III, Heidelberg 1825, 420 S.) das Siegfriedsheim stets als „Pfälzel (sic! corr. Pfalzel!) bei Trier“ bezeichnet. Dass die Pfalzeler Lokaltradition noch in meiner Jugendzeit sehr lebhaft war, habe ich selbst erfahren, als ich vor vielen Jahren bei einem fluchtigen Aufenthalt in jenem Städtchen den Spuren des dortigen Genovefa-Kultus nachging; da wurde mir in einem Hause eine roh gearbeitete Buiste gezeigt, und die Kinder behaupteten eifrig, das sei der "Golokopf". Bekannt ist ja, dass in Pfalzel noch der Kerker Golos gezeigt wird ${ }^{1}$ ). Wie wenig aber diese lokalpatriotische Tradition mit dem ursprünglichen Kern unserer Legende zu schaffen hat, geht daraus hervor, dass die älteren Handschriften ïbereinstimmend den Verräther s of ort nach Entdeckung seiner Schuld, noch am 5. Januar, seine barbarische Todesstrafe erleiden lassen; die einzig genaue Form der Sage schliesst also eine vorübergehende Untersuchungshaft Golos aus.

Aber auch noch heutzutage ist die Pfalzeler Lokalisirung der Legende sehr populär. So heisst es z. B. in der Novelle „Die Schuldige" von Clar a Viebig ${ }^{2}$ ) (Deutsche Revue 1896, 4, S. 151) ${ }^{3}$ ): „Die alte Sage vom Ritter Siegfried auf Burg Ramstein (,Der

1) Vgl. Bärsch a. a. O. und zumal Fr. Menk, Sagen der Mosel, Koblenz 1840, S. 182 f.: („Das Genovefenhaus“). „Noch heutigen Tages zeigt man zu Pfalzel einen alten burglichen Bau, welchen die schöne Legende von der heil. [sic!] Genovefa in romantischen Nimbus hüllt. Man sieht auch dort ein gewölbtes Gemach, welches den Namen Golos-Zimmer trägt, und in dem Keller die Stelle, die des ruchlosen Vogts Kerker gewesen sein soll. Golo selbst ... ist verbannt, in den Ruinen als unstäter Geist umherzuwandeln. Auf einer solchen Wanderschaft verlor er einstmals einen silbernen Pantoffel. ..."

2) Pseudonym für Frau Clara Cohn.

3) Abgedruckt auch in "Linder der Eifel“" Berlin 1897 von derselben Verfasserin. 
Ramstein ist eine alte Burgruine, die sich auf vereinzeltem Hiigel nnweit Ehrang, in lieblichen Kyllthal erhebt", ebenda S. 143) ward wieder lebendig, der dem falschen Knecht sein Ohr lieh, sein nnschuldiges Weib der Untreue zieh und von sich stiess, dass die arme Genovefa in der Höhle tief im Wald Zuflucht suchen musste" u. s. w. ${ }^{1}$.

In diesen Zusammenhang gebört auch folgende Stelle bei A ugust Trinius, Durch's, Moselthal. Ein Wanderbuch, Minden i. W. 1897, S. 208: „Auch eine Sehenswürdigkeit behauptet der ort [Pfalzel] aufweisen zu können. Das ist das Haus, in welchem einst die gute Genoveva gewohnt haben soll, auch der böse Golo seine Strafe empfing. Ein Stück landeinwärts auf dem Wege nach Butzweiler findet man auch noch eine Genovevahöhle." Während aber Clara Viebig an die Richtigkeit der Pfalzeler Lokalüberlieferung glaubt, verwirft $\operatorname{Tr}$ inius dieselbe ${ }^{2}$ ), gewiss mit Recht, indess aus einem verkehrten Grunde, wie alsbald dargelegt werden soll.

Uebrigens gibt es noch keine architektonisch genaue Beschreibung des Pfalzeler sog. Golo- und Genovefahauses. Um so mehr ist zu hoffen, dass Lehfeldt in seinem demnächst erscheinenden Buche „Bau- und Kunstdenkmäler des Rgbz. Trier" das burgähnliche Gebäude nicht übergehen wird.

Nur als Curiosum sei sehliesslich erwähnt, dass F. J. Ki e fer, Die Sagen des Rheinlandes, Köln 1845, S. $103 \mathrm{f}$. sich in völligem Widerstreit mit der ältesten Fassung unserer Legende das Siegfriedsheim, auf dem Schloss Pfalz [!], an dem Zusammenflusse der Mosel und der Saar", also unweit des Fleckens Kontz, denkt!!

8. Trinius a. a. O. S. 208 f. lehnt Pfalzel als Genovefa-Stätte ab mit folgender Begründung: „Schon in der Sage wird der A rdennenwald [sic!] als die wilde Einsamkeit angegeben, in welcher Genoveva geweilt haben soll." Er verlegt also die Legende nach Belgien. Diese Lokalisirung, bei unsern holländischen und belgischen Nachbarn sebr beliebt, steht indess im schroffsten Wider-

1) Vgl. auch ebenda S. 150: „Droben im Walde bei der Genovefaböhle spukte es."

2) "Selbst wenn thatsächliche Ereignisse dieser Sage zu Grunde liegen sollten, so hat sich das. Drama schwerlich in Pfalzel abgespielt" (S. 209). 
spruch zu den Handschriften, wonach Genovefa zwar eine Her. zogin von Brabant war, aber als Gattin des rheinischen Pfalzgrafen ihr Leben im Ma ifeld beschloss. Die fragliche Annahme stiitzt sich nur auf das niederländische Volksbuch "Genovefa", das, wie das deutsche, erst auf Cerisiers' Roman "L'innocence reconnue" zurïckgeht.

9. Unsere Legende liesse sich nur dann mit Luxemburg und seinem romantisch gelegenen, unlängst ebenso sachkundig wie pietätvoll restaurirten Schloss in Zusammenhang bringen, falls der Beweis erbracht würde, dass Pfalzgraf Siegfried von Luxemburg ${ }^{1}$ ) mit dem Gemahl der Pfalzgräfin identisch oder doch wenigstens der Held der Sage geworden ist. Indess Ersteres ist unmöglich; denn die Gemahlin dieses Siegfried hiess Hadewig und nicht Genovefa ${ }^{2}$ ), und dann gab es damals kein „passagi um" (= Kreuzzug gegen die syrischen Sarrazenen!) im Sinne der Handschriften. Mit Recht leugnet also Sauerborn (S.60 Anm.) die Identität des Luxemburger Siegfried mit dem Schlosshern von Hohensimmern. Und sodann ist Pfalzgraf Siegfried, der zweite Stifter von Laach, der nach Trittheim sich am ersten Kreuzzug betheiligte und auch einen Burgvogt (Gottfried von Calw) zurückliess, der Held unserer Legende geworden. Endlich und vor Allem gehört Luxemburg nicht zum Maifeld. Es muss also damit sein Bewenden baben, dass wenigstens die gleichfalls liebliche Melusinasage, wenn auch vielleicht nicht in jeder Fassung, sich unzweifelhaft an das Stammschloss der Lützelburger anlehnt.

\section{Schlussbetrachtung.}

Die Genovefa-Sage ist in den letzten Jahrzehnten, so weit es das nur theilweise vorhandene handschriftliche Quellenmaterial zulässt, allseitig, was Entstehungsgeschichte, Verarbeitung verschiedener Sagenstoffe u. s. w. anbelangt, mit erschöpfender Kritik

1) Siegfried von Luxemburg begegnet zuerst in einer Trier'scien Urkunde rom 17. bezw. 12. April 963 (Beyer I S. 271, Nr. 241).

2) In zwei Urkunden vom 17. Sept. 964 und rom J. 963 gedenkt der Luxemburger Siegfried seiner Gemahlin Hadewig (S. Beyer I, S. 278 f., $\mathrm{Nr} .220$ und wegen der etwas zweifelhaften Datirung Görz, Regesten bei Beyer II, S. 624, Nr. 250; Beyer I, S. 324 f, Nr. 268 und wegen der genaueren Datirung Görz, Regesten a. a. 0. S, 637, Nr. 305). 
untersucht worden. Aber darf die Pietät gegeniiber einer der lieblichsten Legenden des rheinischen, ja des deutschen Volkes sich hieran geniigen lassen? Gewiss nicht! Es eribrigt, noch Manches zu thun.

Die historisch-germanistische Forschung darf vor Allem nicht rergessen, dass der sog. Archetypus, das Seinius'sche Msc., sowie der Hontheim'sche Codex leider noch immer verschollen sind. Ferner: Eine erschöpfende kritisch-ästhetisirende Würdigung der zahlreichen Bearbeitungen unserer Legende in der neueren Literatur, zumal seit Cerisiers, in novellistischer dramatischer Form, sowohl durch Romantiker à la Maler Müller und Tieck, als durch moderne Geister, wie Hebbel u. s.w., eine solche Monographie steht noch aus. Bern b. Se uffert freilich bat recht interessante Nachweise iiber die so reichliche Genovefa-Literatur geboten (s. oben S. 7 f.). Seine schöne Habilitationsschrift sollte in ihrem zweiten Theil Vorläufer für ein grösseres Buch im angedeuteten Sinne sein. Leider war er bisher, wie er mir im vorigen Jahr schrieb, durch massenhafte anderweitige wissenschaftliche, wie amtliche Arbeiten verhindert, sein Versprechen zu erfüllen. Möge bald ein jüngerer Gelehrter bei mehr Musse sich der so dankbaren Aufgabe widmen!

Schon Josef Görres scheint sich für ein derartiges Buch erwärmt zu haben, wenigstens bietet er in seinem herrlichen, während der fröhlichen Heidelberger Zeit (1806-8) verfassten Büchlein „Die teutschen Volksbücher“" (S. 247-249) folgenden geistvollen Vergleich des deutschen Volksbuches "Genovefa" mit den eingehenden dramatischen Bearbeitungen durch die Romantiker Maler Müller und Tieck: „Unter allen den verschiedenen Büchern dieser Gattung [der deutschen Volksbuicher] ist die Genoveva durchaus das geschlossenste und am meisten ausgerundete, stellenweise ganz vollendet, and in seiner anspruchslosen Natitrlichkeit uniibertrefflich ausgeführt. ... Und so war es denn werth, ... zwei treffliche Dichter zu begeistern, Tieck, dass er uns in seinem Gedichte, wie ein Zauberer im Crystalle, die ganze romantiscbe Liebe in einem zarten Licht- und Gluth- und Farbengewebe aus einer lichtklaren Morgenröthe kunstreich zur Gestalt gebildet zeigt, und der Maler Müller ... die Heilige als eine Hünenjungfrau vom Riesengebirge malt, die mit dem Serpent Golo kämpft, der bald in vielfachen Farben brennend und glühend, sie verführerisch umzïngelt, und sie dann das Schwert ergreift und zürnt. ... Unendlich bescheiden 
steht das Volksbuch hinter diesen Effulgurationen der poetischen Kraft, aber in dem rubigen, stillen, lieblichen Schein, in dem es strablt, bricht derselbe poetische Geist, nur leise phosphorescirend, hervor, der in Tiecks und Müllers Werken in lichten Flammen aufbrennt und glüht."

Leider befindet sich die Kapelle Fra u u kir e hen seit Anfang dieses auf die Neige gehenden Jahrhunderts im Zustand traurigster Vernachlässigung (s. Sauerborn, S. 4, Anm. 2, S. 153 nebst Zeichnung I, II, III, Lehfeldt, S. 384-386 und Brüll, S. 9). Möge man über der gewiss berechtigten Fürsorge für die würdige innere Ausstattung der herrlichen romanischen Kirche von Laach mit ibren sechs Thürmen eine Kapelle nicht vergessen, die in innigstem Zusammenbang zu einer der lieblichsten Sagen des rheinischen, ja des deutschen Volkes steht, einer Legende von sogar internationaler Bedeutung! Möge mein Mahnruf nicht zum dritten Mal ungebört verhallen! Beriucksichtige man wenigstens Brüll's schönes Wort (S. 9): „Ehedem ein stattliches Gotteshaus, eine der schönsten und grössten Landkirchen des Ochtendunger Kapitels, ist das ehrwürdige Bauwerk leider trotz seiner früheren Berübmtheit in den traurigsten Verfall geratben, $d \mathrm{em} e \mathrm{~s} s \mathrm{ch}$ on wegen architektonischer Bedeutung, nicht minderaber wegen seiner Beziehungen zu einerder schönsten und beliebtesten Ueberlieferungen der Vorzeit entrissen werdensollte."

\section{Nachträge.}

1. Das Msc. dieser Abhandlung befand sich schon im Besitz der Redaction, da ging mir (am 12. Oct. 1897) folgende gefällige Mittheilung des Herrn Dr. B r üll zu Andernach zu: „Ich werde demnächst $\mathrm{n}$ e u e handschriftliche Beiträge [für die Genovefa-Sage] liefern können, da ich mittlerweile nicht nur den $K u p p$ 'schen Text (= Joh. Andern. in der Urschrift), sondern auch die Abschrift des S e in i u s'schen aus H o n theim's Nachlass gefunden habe." Wir sind also Dank der Umsicht Brttll's in der Handschriftenfrage einen bedeutenden Schritt vorwärts gerïckt. Der sog. Hon thei m'sche Codex ist hiernach mit dem vortrefflichen $S$ e in i u s'- 
schen anni c. 1448 i d e $\mathrm{nt}$ is ch. Jetzt entzieht sich nur noch die Urschrift, der Archetypus, der frühestens dem Ende des 14. Jahrhunders und spätestens etwa dem Jahre 1428 zuzuweisen ist, unserer Kenntniss.

Der S e i n i u s'sche Codex, der also demnächst das Tageslicht wieder erblicken soll, wird jedenfalls zur Lösung einer Ilenge von streitigen $\mathrm{E}$ in zelfragen in erfreulicher Weise beitragen, schwerlich aber die Hauptergebnisse der neueren Genorefa-Forschung erschüttern, da wir schon längst in Johann von tudernach einen vortrefflichen, dem Seinius gleichwerthigen Führer besitzen. Das Weitere wird sich finden, sobald die angelzündigte Publikation Brüll's vorliegt.

Schliesslich ein Wort über eine Einzelfrage: Die erst 1400 bis 1402 erbaute Burg Wernerseck war bisher für die Genovefa-Legende nur durch das E m y i c h'sche Msc. a. 1472 bezengt. Damit muss es auch in Zukunft sein Bewenden haben; denn Briull schreibt mir am 1. November 1897 Folgendes: „Wernerseck kommt in der fraglichen Handsehrift [der Se in i u s'schen] so wenig vor wie bei Johann von Andernach."

2. Erst fast unmittelbar vor Beginn der Drucklegung dieser Abhandlung wurde mir das Buch von Bruno Golz, Pfalzgräfin Genorefa in der deutschen Dichtung, Leipzig 1897. VI u. $199 \mathrm{~S} .8^{0}$ zugänglich, das der oben (in der ,Schlussbetrachungr", S. 30-32) in Erinnerung gebrachten Anregung Bernhard Seuffert's, wenigstens so weit Deutschland und Oesterreich in Betracht kommt, in glänzender Weise gerecht wird und mir so die Erfüllung meines Wunsches grossentbeils gleichsam vorwegnimmt.

Die Einleitung erörtert naturgemäss „Entstehung, Ueberlieferung und Fortbildung der Legende" (S. 1-9) und geht, was nur zu billigen, von den schönen, auch von mir eingerïckten (oben S. 6), Worten von Josef Görres über das deutsche Volksbuch Genovefa aus (S. 1 f.). Mit Fug nennt sodann Golz als verwandt mit unserer Legende „Gris el d is, Hildegard, Krescentia, Hirlanda, Helena, Kaiser Octavian, I t b a v o n T o g g e n bu rg: [die "S'chweizer Genovefa"]" (S. 2).

Zutreffend bemerkt Verf. (S. 3): „Am wahrscheinlichsten ist ... gewiss gemäss der eingehenden Darlegung Seuffert's, dass die Genovefasage weder mythischen noch historischen Ursprungs, son- 
dern zwischen dem Jahre 1325 und etwa 1425 von einem Laacher Mönch verfasst worden sei." Nur zum Schaden der Sache, wie alsbald klar wird, lässt Golz $\mathrm{m}$ e in e eigenen Forschungen (oben S. 1, Anm. 1) völlig unbeachtet (S. 3). Nicht übel handelt Verf. (S. 3) über den Namen Genovefa - leider hat er sich die entscheidende Stelle Greg. 'Tur. hist. Franc. IV e. 26, S. 160-162, ed. W. Arndt ("Monumenta “-Ausgabe!) (s. oben S. 15) entgehen lassen - und den Kult der Pariser Schutzheiligen Genovefa in Maifeld.

S. 3 Anm. 3 meint unser Literarhistoriker: "Das Fortleben der Genovefasage a m Orte ihrer Entstehung im Eifel. g e b i r g e[!!] bezeugen „Die Schuldigen“ (in der Novellensammlung „,Kinder der Eifel") und das aus der Novelle geformte Schauspiel „Barbara Holzer“, Berlin 1897, von C. Viebig. Barbara Holzer bat sich mit ihrem Kind in die einstige Höhle Genovefas gefliichtet und wird nun vom Volk für die wiedererstandene Pfalzgräfin gehalten." Golz hat also gar keine Ahnung von der richtigen Lokalisirung unserer Sage im Sinne der älteren Handschriften: Während letztere übereinstimmend die ganze Handlung auf das $\mathrm{M}$ a if e ld einschränken, spricht Verf. unbestimmt rom Eifelg e birge!!

Besser erörtert Golz die Handschriften in ihrer gegenseitigen Werthschätzung und bevorzugt mit Recht Johann von Andernach (S. 4). Auch die bündige Inhaltsangabe der "L'innocence reconnue" des P. Cerisiers (S. 5-7) ist anzuerkennen.

Abschn. I hat in drei Kapiteln die ,Genovefadramen in Deutschland bis zur Mitte des 18. Jh." zum Gegenstand (S. 10-53). Abschnitt II, wohl der wichtigste, behandelt „Die deutschen Genovefadramen von der Mitte des 18. Jh. bis zur neuesten Zeit" (S. 54-147). Im ersten Kapitel äussert sich Verf. über Plümicke (S. 54 f.) und über Maler (Friedrich) Müller (S. 55-71). Das zweite Kapitel ist der Ti e e k'schen "Genovefa" gewidmet (S. 71-98). Das dritte Kapitel beschäftigt sich zumeist mit dem Münchener Anonymus, sowie mit Raupach (S. 98-107). Das vierte Kapitel gilt Heb bel's "Genovefa" und den Otto Ludwig'schen Fragmenten (S. 101 bis 132).

Das Schlusskapitel würdigt Kulemann's, Ant. Kayser's, Wichmann's, Lachmann's Genovefadramen, sowie die Dingelstedt'sche Tra- 
restie (S. 133-147). Golz wird der Genialität des Malers Müller in seinem Schauspiel "Golo und Genovefa" durchaus gerecht, findet mit Fug Ti e ck's Opus trotz aller Vorzüge im Einzelnen vielfach langweilig and bricht nicht minder berechtigt iber die H e b bel'sche "Grenovefa" den Stab. Der sonst vortreffliche Dramatiker behandelt eben den spröden naiven Stoff zu subjectiv und nodern. Der ausserordentlich schweigsamen Pfalzgräfin hat er die Maske seiner treulos verlassenen ersten Braut, der Hamburger Elisabeth, angelegt, er selbst, der sein Verhalten bereut, ist Golo. Daher erscheint der Letztere nach reckenbaften Anfängen in aufdringlicher Weise als ein allmählich zum Verbrecher herabsinkender sentimentaler Schwärmer, der nicht einmal den Muth des Frevlers hat, vielmehr sofort seine Unthaten bereut. Die Scene, wie er zuletzt als reuiger Sünder sich die Augen aussticht, ist geradezu widerlich; auch der seiner lieblichen Gemahlin gegenüber in der Abschiedsscene (im 1. Akte) allzu kühl zurückhaltende Pfalzgraf Siegfried wirkt abstossend. So kommt es denn, dass das Schanspiel, das anfangs noch die sonstige Virtuosität Hebbels erkennen lässt, je weiter es vorwärts schreitet, um so ungeniessbarer wird. Es war also ein grosser Akt von Pietät gegenüber dem sonst mit Recht gefeierten Dichter der ,Judith“, der „Nibelungen“, der „Maria Magdalena", dass die Direction des Berliner deutschen Theaters unlängst ihrer kleinen, aber andächtigen Gemeinde die missglückte Hebbel'sche „Genovefa" nach fast 50 jähriger Pause in sorgfältiger Inscenirung wieder vorgefibht hat.

Mit berechtigter Anerkennung spricht Golz (S. 130) von den tïchtigen Otto Ludwig'schen Fragmenten „Genovefa". Professor Suphan, Direktor des Goethe-Schiller-Archirs zu Weimar, bewirkte unserem Verf, bei der inzwischen verstorbenen Grossherzogin Sophie von Weimar die Erlaubniss für litterarische Verwerthung der Genovefafragmente Otto Ludwigs (Vorwort S. V). Golz konnte uns also (im Anbang S. 173-199) mit einem genaueren Text dieser genialen Bruchstücke beschenken, als es einst einem Moritz Heydrich (Otto Ludwig, Skizzen und Fragmente, Leipzig 1874 , S. 369-383) möglich war.

Im dritten Abschnitt, „[Genovefa-]K om pos i ti o nen" (S. 148153) eröffnet ein $\mathrm{Jos}$ e ph Hay d $\mathrm{H}$ den Reigen. Dann folgen Huth, A. W. A m bros und zuletzt R ob e r t S e b u ma nn (S. 149 -153). Dass des letztern "Genoveva, Oper in 4 Akten" so wenig bühnengerecht ist und darum auch so selten über die Bretter geht, 
hängt wohl in erster Linie mit dem Mangel an Handlung, an dramatischer Belebtheit zusammen, der durch das nach Tieck und zumeist Hebbel bearbeitete Libretto bedingt ist.

Abschn. IV bringt die Verwerthung unserer Legende für „Volksschauspiel“ (S. 155-159) und „Puppenspiel" (S. 159 -164). Die Ausfithrungen über "Genovefa" im Marionettentheater sind verdienstlich und gehen noch ïber das Seuffert'sche Material hinaus, sind aber noch nicht erschöpfend. Ich vermisse da zllnäcbst eine kurze Erwähnung des bei Jung und Alt beliebten Puppenspiels "Genoveva, Tranerspiel zum Dutlaache (sic!) in 5 Akten" des Kölner Hänneschen-Theaters. Diese originelle Bübne will zwar in erster Linie Parodien bieten, "Genovefa" ist aber sicher keine Travestie. Im Gegentheil: Der alte naive Stoff, wie er im deutschen Volksbuch vorliegt, ist im Wesentlichen beibebalten - rügen möehte ich, dass Hänneschen, auf der Siegfriedsburg. bedienstet, sich zum Helfershelfer des bösen Golo hergibt und gar den armen Koch Drago vergiftet! -, auch die Lokalisirung ist durchweg zutreffend, nur dass, was schon der Titel andeutet, „Hänneschen" und „Tünnes" bemüht sind, durch zahllose Kölnische "Witze" den Ernst der Tragik zu mildern.

Weiter hat sich Golz ein Puppenspiel ,Siegfried und Genovefa oder Golo der falsche Burgvogt, ein Ritter, Tranerspiel in 7 Aufziigen" entgehen lassen. Es gehörte zum Spielplan des von einem Mechaniker Jordan (aus St. Wendel, Rgbz. Trier) geleiteten Marionettentheaters, das zwischen 1857 und 1871, zumeist. 1857-60 im ganzen Rgbz. Trier Gastrollen gab. Ich selbst war im Närz 1857 zu Wittlich Zeuge einer solchen Aufführung. Hännesehen ist da durch Kasperle ersetzt; dieser sonst so lustige Bursche dämptt sichtlich seinen Humor, um den Ernst der Handlung nicht zn stören. Der ganze Aufbau des Stückes vollzieht sich in getrenem Anschluss an die alteren Handschriften und das deutsche Volksbuch. Demgemäss ist die Lokalisirung eine genaue, so z. B. heisst das Siegfriedsheim gan\% richtig $\mathrm{Hoh}$ ensimmern. Die beiden ersten Aufzizge fübren uns Siegfrieds Abschied von seincr Gemahlin und die erfolglosen Versuche des Burgvogts Golo vor, die ebeliche 'l'reue der Pfalzgräfin zu erschüttern.

Im dritten Aufzug bezichtigt der ob soleher Abweisung gekränkte Golo seine Herrin und den Koch Drago des Ehebruchs, lässt Genovefa einkerkern, die im Burgverliess ihrem Schmerzenreich das Leben gibt, und den angeblichen Verführer ermorden. 
III vierten Aufzug erwirkt Golo zu Strassburg von dem dureh die Hexe Piata getäuschten Pfalzgrafen den Befehl zur Hinrichtung der vermeintliehen Ehebrecherin. Im fünften Aufzug wird Genovefa mit ihrem Söhnchen von den beiden Henkersknechten geschont, muss sich aber verpflichten, den Rest ihrer Tage in der Wildniss zuzubringen. Im sechsten Aufzug erscheint dem Pfalzgrafen der Geist des ermordeten Drago und ruft ihm drohend zu: ,Genovefa ist unschuldig"c. Siegfried bereut jetzt zu spät sein ibereiltes Urtheil. Um ibn zu zerstreuen, veranstaltet Golo am Vorabend von Dreikönig eine solenne Jagd. Im Schlussaufung findet Siegfried Mutter und Sohn in der Höhle wieder. Genovefas Unschuld kommt zu Tage, und der Verräther Golo wird trotz der Fürbitte der Pfalzgrïfin von vier zottigen Ochsen zerrissen; seine Mitschuldige Piata erleidet den Feuertod.

Im fünften Abschnitt „Gedichte" (S. i6̌-169) erwälnt Golz Simrocks herrliches Poëm "Siegfried und Genovefa" sowie das Epos "Genovefa" des katholischen Pfarrers Weissbrodt.

Eine ästhetisirende kritische Würdigung der Pfalzgräfn in der sonstigen Weltlitteratur, namentlich in England, Spanien, Frankreich, Italien und Nordamerika, steht noch aus.

Vielleicht nimmt sich Golz, der sich mit seiner schönen Erstlingsschrift so vortheilhaft in die respublica literarum eingefiihrt hat, auch dieser dankbaren Aufgabe an.

Ich will jetzt auch meinerseits eine Kleinigkeit bei. stenern. Es ist wohl nur Wenigen bekannt, dass auch Fra u von Stä̈l, die gefeierte Verfasserin der "Corinne“, sich am Genovefamotiv versucht hat. In ihren „Oeurres“, XVI, Paris 1821 findet sich „Genviève de Brabant. Drame en trois actes et en prose composé en 1808“, S. 21-71. Dieses Schanspiel ist noch weniger bühnengerecht als die Hebbel'sche "Genorefa“. Golo - man sollte es nicht glauben - tritt hier nicht einmal als handelnde Person auf!! Nar der Todte spricht zu der lebenden Pfalzgräfin! - Mit dem Sagenstoffe selbst wird mit einer Willkiir umgesprungen, die selbst einer genialen Dichterin und Weltdame nicht $\mathrm{zu}$ verzeihen ist. $\mathrm{Da}$ soll Siegfried erst im $\mathrm{f} \mathfrak{u} \mathrm{n} f-$ te n Jabre einer gliucklichen Ehe gegen die Sarrazenen zu Felde gezogen sein. Während selbst Cerisiers und seine Nachbeter nur 
e in Kind Siegfrieds und Genovefas, den im Kerker geborenen Schmerzenreicl, kennen, weiss die Staël von $z w$ ei Kindern zu berichten. Ibr zufolge hatte der Pfalzgraf, als er Golo zum Burgvogt ernannte, bereits einen 4jährigen Sohn Namens Adolph (!!); im Kerker kommt eine Tochter Genovefas zur Welt (!). Weiter dehat die Verfasserin den Aufenthalt der Pfalzgräfin in der Wildniss, der nach der Handschrift 6 Jahre und 3 Monate dauerte, auf $\mathrm{zehn}$ Jahre ans. Nach diesem Zeitraum verlässt Genovefa mit ihrer Tochter (!) den Wald, begegnet einem Eremiten, der ih r d as Grab des reuigen Golo zeigt und die seltsame Insehrift "Celui que cette tomberenferme ici même n'a pu trouver le repos: (S. 34 ff., Acte II, scène I) deutet. Der Einsiedler händigt der Pfalzgräfin ein ihre Unschuld bezengendes Schreiben des sterbenden Verräthers ein. Später begegnet sie Siegfried und ibrem jetat etwa 14jährigen Knaben (!); sie zeigt dem Gemahl das Aktenstiick Golos und wird von dem seine Uebereilung bereuenden Pfalzgrafen wieder als Gemahlin aufgenommen. Natiirlich ist anch die Lokalisirung eine durchaus unrichtige: Die Handlung spielt sich in Belgi en ab; Siegfried heisst „comte de Brabant"!

3. Gleichfalls erst vor Thoresschluss konnte ich noch von der kurzen, aber inbaltreichen Studie von J o h n M e i e r, ,Zur Entstehungsgeschichte der Genovefa-Legende", Bernhard Seuffert's Vierteljabrsschrift für Litteraturgeschichte III, 1890, S. 363-365 Kenntniss nehmen.

In der oben (S. $15 \mathrm{f}$. 25) besprochenen Urkunde vom Mai 1255 (Nittelrbein. Urkundenbuch III, 941) kommt ein Wald vor Namens "sancte Genovefe G e r e $\mathbf{u} \mathbf{h} \mathrm{t}^{\text {"c }}$. Meier liest nun mit Recht .... "Gerehnt" und hemerkt zutreffend: „So und nicht Gereu ht ... stebt in dem zu Coblenz im Staatsarchiv befindlichen 0 rigin a l. Diese Mittheilung verdanke ich dem ... Staatsarchivar Dr. Becker" (S. 364 Anm. 1). "Gereuht" ist also bloss Le se fe b le r im Mittelrhein. Urkundenbuch.

Unter Gerehnt will Meier entweder gerente $=$ nhd. rente oder (minder wahrscheinlich) eine Kollectivbildung zu rante, Schössling, schlanker Fichtenstamm verstehen. Im ersten Falle mag man annehmen, ,dass der Wald ursprünglich eine Rente der „Genovefa-Kapelle zu Andernach war" (Meier a. a. 0.). Mit Un- 
recht hält es aber derselbe Forscher (S. 365) nicht für unmöglich, lass der Verfasser der Legende oder seine Zeitgenossen, an die Flurlezeichnung anknüpfend, als den Anffindungsort der Genovefa jenen Wald bezeichneten, und dass auf diesem Platze später die Kapelle in Frauenkirchen ... erbaut ist". Denn erstens, aus architektonischen Gründen dürfen wir annehmen, dass die Kapelle Frauenkirchen schon im $\mathrm{z} w$ ölften Jahrh. existirte (s. Lehfeldt a. a. O. S. 384f. und oben S. $10 \mathrm{f}$ ), der Dichter der Legende sie also bereits vorfand. Sodann ist es mehr als gewagt, jenen Wald St. Genovefe Gerehnt, den man heute kaum mehr identificiren kann, gerade in die nächste Umgebung von Frauenkirchen zu verlegen. 